\title{
Source of arousal and memory for detail
}

\author{
TERRY M. LIBKUMAN, PENNEY NICHOLS-WHITEHEAD, \\ JAMES GRIFFITH, and ROSALIE THOMAS \\ Central Michigan University, Mt. Pleasant, Michigan
}

\begin{abstract}
Two questions about the relationship between arousal and memory were investigated: First, does the source of arousal influence memory, and, second, what impact does arousal have on memory for detail? In Experiment 1, physiological arousal (running or not running in place) was factorially combined with emotional arousal (viewing a neutral or an emotional slide sequence). Recognition memory was tested for gist, central detail, and background detail. Experiments 2 and 3 were similar to Experiment 1 , with the exception that a cued recall task was used in Experiment 2 and physiological arousal was manipulated with stationary biking in Experiment 3 . The results of these experiments indicated that physiological arousal had little impact on memory and that emotional arousal led to improvements in memory for both central and background detail. Overall, these results supported the notions that the source of arousal is an important determinant of an event's memorability (Christianson, 1992a) and that emotional arousal serves to enhance the scope of memory (i.e., flashbulb memory; Brown \& Kulik, 1977).
\end{abstract}

We are interested in two questions concerning the relationship between arousal and memory. First, does it matter how one is aroused-that is, does inducing arousal through different means lead to differences in memory? Second, what impact does arousal have on memory for central and peripheral (background) details?

The answer to the first question depends on the nature of the arousal. The traditional view, possibly beginning with Yerkes and Dodson's (1908) inverted-U, assumes that arousal is a unitary process with nonspecific or generalizable properties. Similarly, Duffy (1962) characterized arousal as the "excitation of the individual as a whole" (p. 3). More recently, and consistent with the unitary view, Revelle and his colleagues (e.g., Humphreys \& Revelle, 1984; Revelle \& D. A. Loftus, 1992) referred to the arousal construct as the nonspecific energetic or intensity component of motivation. The traditional view, however, has had its critics. Neiss (1988a, 1988b) and Christianson (1992a), for example, have taken the position that the inverted- $U$ is irrefutable and therefore should be "retired."

The alternative view is to characterize arousal as a multistate or multidimensional process (Neiss, 1988a, 1988b). This view is consistent with the earlier classical work of Lacey (1967), in which he divided arousal into the physiological, the cognitive, and the behavioral. Given the lack of solid theory and the paucity of data, Broadbent's (1971) position may be the most tenable--that is, as a practical matter, it may be better to operationally separate the various indices of arousal into the physiological and the

This research was supported by a Central Michigan University Faculty and Creative Endeavors grant awarded to T.M.L. We thank the following individuals for their thoughtful comments: Elizabeth Loftus, Hajime Otani, Debra Poole, Daniel Reisberg, and Charles Stabler. Correspondence concerning this paper should be addressed to T. M. Libkuman, Department of Psychology, Central Michigan University, Mt Pleasant, Michigan 48859 (e-mail: terry.m.libkuman@cmich.edu). psychological, for example. It is hoped that this view, if taken seriously, would lead to empirical investigations exploring in more detail the relationship between types of arousal and their impact on memory. Systematic exploration would be particularly important, given the lack of any persuasive explanation concerning the sources of autonomic nervous system activation (Mandler, 1992).

Only a few studies have compared different ways of inducing arousal, especially within the framework of memory research. Christianson and Mjörndal (1985) compared the memory performance of subjects who were aroused through adrenaline injections with that of salineinjected controls. No differences in memory for neutral pictures were found between the two groups. Christianson, Nilsson, Mjörndal, Perris, and Tjellden (1986) compared adrenaline-injected subjects who viewed neutral pictures with saline-injected subjects who viewed emotionally arousing pictures. Christianson et al. reported that the emotionally arousing pictures led to decrements in memory performance (i.e., amnesia). The data from these studies led Christianson and his colleagues to conclude that the source of arousal is important in determining its influence on memory. In particular, the source of arousal must be relevant to the to-be-remembered event before it can have any impact on memory.

One of the purposes of the present research was to further explore the effects of different sources of arousal on memory. In particular, two sources of arousal were manipulated: physiological arousal, induced by stationary running or biking, and emotional arousal, induced by slides containing scenes of a surgeon performing an operation. The present factorial design (i.e., presence or absence of physiological arousal factorially combined with presence or absence of emotional arousal) permits us to look at the interactive nature of different sources of arousal, something that has not been examined in the literature. 
The second question (i.e., what impact does arousal have on memory for central and peripheral details?) has also led to a number of alternative views. The more recent view suggests that memory for both central and peripheral information should improve with arousal. Flashbulb memories (Brown \& Kulik, 1977; Conway, 1995) are assumed to contain relatively permanent and complete photographic detail of an emotional event. Brown and $\mathrm{Ku}-$ lik's flashbulb mechanism parallels Livingston's (1967) neurophysiological now print theory: If an event is sufficiently arousing and is highly consequential to the individual, a now print command is given. The brain then permanently records all available information (i.e., all sensory input and cognitions immediately prior to and during the event), leading to a vivid, detailed, and accurate account of the emotional event as well as of the details surrounding the emotional event. In addition to Brown and Kulik, evidence favoring this view includes Bohannon's (1988), Christianson's (1989), and Heuer and Reisberg's (1990) research. Finally, and most recently, the basic assumptions and empirical findings of this view have been incorporated into a causal model, using a structural equations approach (Conway et al., 1994). However, despite the development of sophisticated modeling procedures, as well as the inherent interest in the flashbulb notion, there is considerable debate concerning the nature of the phenomenon. For example, to what extent can flashbulb memories be explained on the basis of ordinary memory mechanisms (Cohen, McCloskey, \& Wible, 1988, 1990; McCloskey, Wible, \& Cohen, 1988; Pillemer, 1990; Schmidt \& Bohannon, 1988)? In addition, the evidence supporting this position is largely anecdotal, leading to questions concerning the veracity of the reported memories (McCloskey et al., 1988). Studies that have compared individual accounts of traumatic events have reported numerous contradictions and discrepancies (e.g., McCloskey et al., 1988). Furthermore, Weaver (1993) concluded that individuals simply have more confidence concerning their memory for traumatic events, rather than there being any differences in their memories per se. Finally, the experimental evidence supporting the position that arousal leads to improvement in both central and peripheral information is scarce. In fact, we were able to find only one source that supported this view (Heuer \& Reisberg, 1990), and this study carries with it interpretative problems concerning the definition of what constitutes central and background detail. This issue will be discussed in more detail later in this paper.

The more popular alternative position (Easterbrook, 1959) assumes that high arousal narrows the focus of attention, which, in turn, allows the organism to focus on only the more salient cues. This hypothesis leads to the prediction that the central details of an event should be well remembered, whereas the peripheral details should not. The earlier data supporting this view were inconclusive (Eysenck, 1976, 1977). However, authors of more recent reviews of this literature (Christianson, 1992a; Heuer \& Reisberg, 1992) have supported the theory.

This theoretical account has been used to explain the weapon focus effect that has been reported in the eyewitness literature. The weapon focus effect is assumed to occur, for example, when someone is an eyewitness to a robbery or shooting. Presumably, the eyewitness will be able to describe the weapon in great detail but will possess little if any memory about the perpetrator or other aspects of the event (Cutler, Penrod, \& Martins, 1987; Kramer, Buckhout, \& Eugenio, 1990; E. F. Loftus, 1979; E. F. Loftus, G. R. Loftus, \& Messo, 1987; Maass \& Kohnken, 1989). However, there are studies that have failed to provide support for the weapon focus theory (see Steblay, 1992, for a meta-analysis of these data). In addition, many of these studies are difficult to compare and interpret because of differences in methods and to-be-remembered material as well as differing definitions of central and peripheral information (Christianson, 1992b; Heuer \& Reisberg, 1992).

The variability in the definitions of central and peripheral information is particularly troublesome, because it might be related to the different conclusions across studies. Heuer and Reisberg (1992), for example, have suggested that memory for detail is dependent on the retention interval: Short delays are assumed to lead to inferior memory for detail, whereas long delays are assumed to lead to superior memory for detail. Christianson (1992a) has interpreted this literature as indicating that researchers who have focused on central detail or gist have concluded that emotional arousal improves memory, whereas researchers who have focused on peripheral detail have concluded that emotional arousal impairs memory. Obviously, these interpretations are dependent on what constitutes central and peripheral detail. Heuer and Reisberg (1992) suggested that we do not know which partition of central and peripheral is the correct one and, therefore, it may be best to treat the categorization of the to-be-remembered material as an empirical matter. In other words, investigations in which central and peripheral detail are defined and treated differently may be of some value in clarifying the issue. Our treatment of this issue is based on the Heuer and Reisberg (1990) and the Burke, Heuer, and Reisberg (1992) studies. In the former study, central and peripheral details were defined as "elements central to the story ... and details peripheral to the story" (p. 497), respectively. Using recognition and recall measures, their results indicated that, when subjects were aroused, memory performance increased for both central and peripheral detail. In the latter study, recognition test items were categorized into four types of to-beremembered information: Items previously categorized as central detail were subdivided into gist and basic-level visual information, and items previously categorized as peripheral detail were subdivided into central detail and background detail. Although the results of this study were complicated, the data basically indicated that, when sub- 
jects were aroused, memory for central detail improved, whereas memory for background detail declined.

In the present series of three experiments, we have replicated much of the methodology of the Heuer and Reisberg (1990) and Burke et al. (1992) experiments. However, because we were not able to empirically separate basic-level visual information from gist, these categories were combined into one. For the purpose of clarity, we will call this combined category gist throughout the paper. In Experiment 1, we examined the role of physiological and emotional arousal on memory for detail. The purpose of the second experiment was to extend the generality of the findings from our first experiment (where a recognition measure was used) by using a cued recall measure of memory. Finally, the third experiment examined the possibility that declining arousal levels (in Experiments 1 and 2, arousal was induced through stationary running prior to encoding but was not maintained during the encoding interval) may be responsible for the effects in Experiments 1 and 2. In the third experiment, physiological arousal was maintained by stationary biking during encoding.

Overall, the design for the three experiments involved source of arousal (physiological and emotional) and type of information (central detail, background detail, and gist). In these three experiments, the predictions were similar. If the multiple state model proposed by Christianson is correct, physiological arousal should not have any impact on any measure of memory (i.e., central, background, or gist), whereas emotional arousal should lead to enhanced memory. Furthermore, if the Easterbrook (1959) hypothesis and the conclusions of Christianson (1992a) and Heuer and Reisberg (1992) are correct, emotional arousal should lead to memory enhancement for central but not for background detail (i.e., the weapon focus effect; E. F. Loftus, 1979). On the other hand, if flashbulb theory (Brown \& Kulik, 1977) is correct, emotional arousal should lead to memory enhancement for central and background detail. No predictions were made for gist, although it could be argued that memory improvement should occur for this material as well.

If the unitary view of arousal is correct, memory performance for physiological and emotional arousal should mimic the predictions for emotional arousal in the multistate model- that is, only main effects should occur for both types of arousal. In other words, the effects should be additive, not multiplicative.

\section{EXPERIMENT 1}

The main purpose of Experiment 1 was to determine the influence of physiological and emotional arousal on recognition memory for the central and background, or peripheral, aspects of an event. Although this study replicates, in part, the experiments of Burke et al. (1992), it is important to note that the Burke et al. study did include a delayed testing condition, whereas our study did not. Because the effects of interest in the Burke et al. study were most evident, particularly for central and peripheral details, in the immediate testing condition, we did not believe that it was necessary to include a delayed testing condition.

\section{Method}

Subjects. Eighty undergraduate students from Central Michigan University were recruited from introductory psychology classes. The subjects were randomly assigned to the four treatment conditions, with the restriction that each condition contain an equal number of women and men.

Materials and Apparatus. The stimuli consisted of two sets of 12 slides that were developed by Heuer and Reisberg (1990). ${ }^{1}$ Each slide was accompanied by a taped narrative that was also developed by Heuer and Reisberg (1990) and revised by us. A Kodak Carousel 850 slide projector was used to project the slides onto a screen at a size of approximately $18 \times 24 \mathrm{in}$. and a height of approximately $31 / 2 \mathrm{ft}$. The subjects were seated approximately $6 \mathrm{ft}$ from the screen. A Wollensak $3 \mathrm{M}$ tape recorder was used to present the taped sentences. The tape recording incorporated a tone to signal automatic advancement of the slide projector.

The slides depicted two versions of a story about a mother and a son visiting the father at work. In one (neutral) version, the father is a mechanic and fixes a car. In the other (emotional) version, the father is a surgeon and performs an operation. The slide presentation had three phases, with the emotional manipulation taking place in Phase 2. In Phase 1, Slides 1-3 and the corresponding taped narratives were identical for both stories, showing the mother and son on their way to visit the father at work. Slide 4 showed the father's workplace - a garage in the neutral version and a hospital in the emotional version. The second phase contained the four critical slides (5-8), which differed for the two conditions. In the emotional condition, the son watches the father perform an operation on a patient. For the neutral condition, the son watches the father repair the engine of an automobile. The differing slides were matched as closely as possible for content and visual form. The narrative sentences for each slide were matched as closely as possible for structure and length. In Phase 3 (the final phase), Slides 9-12 and the corresponding narratives were the same for both conditions, showing the mother leaving the father's workplace, making a phone call, and hailing a cab. Phase delineations were made for purposes of analyses only and were not apparent to the subjects.

In the Burke et al. (1992) and Heuer and Reisberg (1990) studies, the slides were also subdivided into three phases. However, these authors included the first three slides in Phase 1 and the next five slides in Phase 2, with the remaining four slides being in Phase 3. It is possible, therefore, that any differences in results between the Burke et al. and Heuer and Reisberg (1990) studies and our studies may be a function of the placement of Slide 4 . On the basis of our view, whether Slide 4 (for both the hospital and the garage slide sequences) is placed in Phase 1 or Phase 2 is dependent on the perceived reactivity and emotionality of Slide 4 in the hospital slide sequence. If the perceived reactivity and emotionality of this slide is similar to those for the slides in Phase 1, Slide 4 should be placed in Phase 1. If the responses are similar to those for the slides in Phase 2, it should be placed in Phase 2. In the Burke et al. and Heuer and Reisberg (1990) studies, as well as in the present studies, rating scale data on reactivity and emotionality of the slide presentation did not address this issue, because the ratings were based on the entire slide sequence.

In order to determine the perceived reactivity and emotionality of each slide, data were collected on 36 introductory psychology students. These students were randomly assigned to the hospital or the garage slide sequence. Each slide was shown for $10 \mathrm{sec}$. During this interval, the subjects were instructed to view the slide and rate the 
emotionality and their responses, using the same rating scale instrument (described in the following paragraph) that was used to evaluate the entire slide sequence in the present experiments. Analyses of these data indicated that only Slides 5-8 in the hospital presentation elicited agreement, indicating that these slides were emotionally arousing and that the subject's response to them was emotional. Slide 4 was therefore placed in Phase 1 for all analyses reported in this paper. Would the results of our studies be any different if Slide 4 was placed in Phase 2? The results when Slide 4 was in Phase 1 were compared with the results when Slide 4 was in Phase 2 for all of the memory measures in all of our studies. The outcomes of these analyses indicated that the results were essentially the same, regardless of the placement of Slide 4 .

A Polar Favor heart rate monitor was used to track the subject's heart rates throughout the slide presentation, to assess arousal. The monitor was strapped around the subject's body at the level of the solar plexus. A 9-point Likert scale (anchored on one end with strongly disagree [a scale value of -4] and the other end with strongly agree [a scale value of +4$]$ ) was used to rate the emotionality and the subject's reactions to the entire slide sequence. A questionnaire that contained questions (unrelated to the content of the slides and narrative) about how long the subjects tended to think about events before and after they occurred acted as a filler task temporally separating the slide presentation and the recognition test.

Content validity of the recognition test. A content validity study was conducted on the recognition test used in the Burke et al. (1992) study. This test was originally developed by Heuer and Reisberg (1990) and then modified by Burke et al. Four graduate students who were not part of the study were trained as judges and then asked to categorize the questions according to the definitions provided by Burke et al. There was very little consensus (an overall content validity coefficient of .35) among the judges as to the correct categories for the questions. Disagreement occurred largely in separating gist from basic-level visual information and central from background detail. Test items were revised, wherever possible, to remove ambiguities and to make sure that options agreed with the information in the slides and the narratives for both the arousal and the neutral conditions. The narratives we used were the same as the narratives listed in the appendix (p. 506) of the Heuer and Reisberg (1990) paper, with the exception of Slides 9,11 , and 12 . In the Heuer and Reisberg (1990) paper, Slide 9 narratives for the neutral and arousal conditions were "mother leaves the garage being late for her job" and "mother leaves the hospital upset by what she saw," respectively. In Slide 11 , the neutral and arousal narratives were "mother apologizes for her delay to her boss" and "mother asks her boss to get the day off," respectively. In Slide 12, the neutral and arousal narratives were "she tries to hail a cab downtown at the number 3 bus stop" and "she tries to hail a cab home at the number 3 bus stop," respectively. The neutral and arousal narratives we used for Slides 9,11 , and 12 were identical to their neutral narratives, with the exception that, in Slide 9, the word hospital replaced the word garage in our arousal condition.

Some test items could not be altered satisfactorily and were eliminated entirely. New items were added to equalize the number of items across conditions, categories, and phases. The target number was 10 items per category, per phases, for both story conditions.

The category of basic-level visual information was combined with gist, because judges could not consistently separate the items for these categories. In addition, the main interest of the present study was the contrast between central and background detail, and, therefore, the separation of basic-level visual information and gist was unnecessary.

Initially, the judges were trained with a short slide story with accompanying narratives, as well as individual slides that were unrelated. A companion sample test was used to provide each judge with realistic practice. The judges were given written definitions and instructions and immediate feedback on the sample test, before going on to judge the items on the revised memory test. Unlimited time was allowed for the judges to view the slides, read the narratives, and make their evaluations. Content validity was quantified by using a 4-point rating scale to assess the relevance of each test item for each category of information. Ratings were then dichotomized into two categories of relevance-weak or strong. Only items judged to be strongly relevant by a $75 \%$ or greater consensus among the judges were retained for the final version of the test. All the other items were revised and judged again or omitted entirely. Overall, the revised version of the four-alternative forced-choice recognition test contained 87 questions in the emotional version and 90 questions in the neutral version. Items were distributed as evenly as possible, with 8 to 10 items per category, per phase. Fifty-three percent of the items had a content validity of 1.00 , and $47 \%$ of the items had a coefficient of .75 . The test had an overall content validity coefficient of .88. Questions pertaining to Slides $1-3$ and 9-12 were identical for both emotional and neutral conditions. Questions pertaining to Slides 4-8 were matched as closely as possible for the two conditions. The questions tested memory for three categories of information: gist, central detail, and background detail. An example of a gist question was "mother and son are ..." The four alternatives were: entering a building, passing a playground, buying cigarettes, and walking down the sidewalk. The correct answer was the last alternative. An example of a central detail question was "what is the color of the door?" The four alternatives were: blue, brown, green, and black. The correct answer was the first alternative. An example of a background detail question was: "one of the objects that spilled out of the car was..." The four alternatives were: a briefcase, an airline bag, a spare tire, and a toolbox. The correct answer was the second alternative. The questions pertaining to the three categories were distributed as evenly as possible across the test. The questions were presented in the same sequence for all the subjects, because some questions presupposed answers to previous questions.

Design. The design was a $2 \times 2 \times 3 \times 3$ factorial, with physiological arousal (arousal and nonarousal) and story type (emotional and neutral) as between-subjects variables and phase (1-3) and category of information (gist, central detail, and background detail) as withinsubjects variables. Each category of information was analyzed separately, using percent correct recognition as the dependent measure.

Procedure. The subjects were tested individually. The experimenter greeted and seated each subject and then read the instructions aloud. The experimenter informed the subjects that the purpose of the study was to investigate the effects of visual stimuli on physiological arousal. The instructions also indicated that the subjects might be required to run in place and then asked them to sign a consent form stating that they knew of no medical or other reason why they should not participate. Approximately $5 \mathrm{~min}$ after the subjects were seated, the experimenter took a baseline measure of heart rate.

After a brief demonstration by the experimenter, the subjects in the physiological arousal condition were asked to run in place for $1 \mathrm{~min}$. Trouvé and Libkuman (1992) reported that this procedure increases heart rate by about $60 \%$ and that it takes about $6-8 \mathrm{~min}$ for heart rate to return to baseline. The time of increased physiological arousal is, therefore, well within the boundaries of the time it takes to view the slides (about $84 \mathrm{sec}$ ). The subjects in the nonphysiological arousal condition were required to sit for $1 \mathrm{~min}$. The physiological arousal subjects were again seated, and a second measure of heart rate was taken. A second baseline measure of heart rate for the nonphysiological arousal subjects was taken $1 \mathrm{~min}$ after the first measure. The slide presentation then began immediately and lasted approximately $84 \mathrm{sec}$. Each slide was shown for $6 \mathrm{sec}$, with a 1 -sec interval between slides. Each taped narrative began approximately $1 / 2 \mathrm{sec}$ after the corresponding slide appeared and lasted approximately $4 \mathrm{sec}$. Heart rates were monitored throughout the presentation, with individual measures taken approximately 2,4 , and $6 \mathrm{sec}$ after each slide began. After viewing the slides, the subjects were given the emotionality scales and a filler task that took $10-15 \mathrm{~min}$ 
to complete. The recognition test was then administered. After the test was completed, the subjects were given a written debriefing and thanked for their participation.

\section{Results}

Cell means and standard errors for all of the dependent measures for the three experiments are presented in tabular form in the Appendix.

Heart rate data. Initial baseline heart rates ranged from 51 to 110 beats per minute (bpm). A 2 (physiological arousal) $\times 2$ (story) analysis of variance (ANOVA) revealed no significant effects. Mean heart rates ranged from 76 to $79 \mathrm{bpm}$. For the second baseline measurement, taken after physiological arousal was manipulated, heart rates were significantly higher for the subjects who ran in place $(M=139 \mathrm{bpm})$ than for the subjects who did not run in place $\left[M=80 \mathrm{bpm} ; F(1,76)=249.87, M S_{\mathrm{e}}=\right.$ $276.74, p<.0001]$.

Heart rates were recorded three times during each slide, approximately every $2 \mathrm{sec}$. The second measure (taken approximately $4 \mathrm{sec}$ after slide onset) for each slide was used to calculate mean group heart rates for each phase. A $2 \times$ $2 \times 3$ (physiological arousal $\times$ story $\times$ phase) ANOVA revealed significant effects for physiological arousal $\left[F(1,76)=11.92, M S_{\mathrm{e}}=981.01, p<.0009\right]$, phase $\left[F(2,152)=174.45, M S_{\mathrm{e}}=20.05, p<.0001\right]$, and the physiological arousal $\times$ phase interaction $[F(2,152)=$ $97.51, p<.0001]$. The interaction indicated that the mean heart rates for the subjects who ran in place started much higher and then dropped, relative to the subjects who did not run in place. No significant effects were found for story.

The second measure of heart rate was used because it would allow some time $(4 \mathrm{sec})$ for the effects of the slides on heart rate to materialize. However, in order to replicate the method used by Burke et al. (1992), the lowest heart rate measure for each slide was also used to calculate mean heart rates for the nonphysiologically aroused subjects. Unfortunately, these measures were not recorded for the first 9 subjects, so only data from the last 31 subjects in the nonphysiological arousal conditions were available for analysis. The 2 (story) $\times 12$ (slides) mixed effects ANOVA revealed only a significant main effect for slides $\left[F(11,319)=12.38, M S_{\mathrm{e}}=10.92, p<.0001\right]$. In general, mean heart rates declined from Slide $1(M=$ 43.93) through Slide $3(M=80.10)$ and then essentially remained stable for the remaining nine slides.

Rating scales. Analyses of the emotionality rating scale data, using $2 \times 2$ (physiological arousal $\times$ story) ANOVAs, revealed a significant story effect for both the emotionality of the slide presentation $[F(1,76)=51.72$, $\left.M S_{\mathrm{e}}=3.31, p<.0001\right]$ and the subjects' responses $\left[F(1,76)=48.34, M S_{\mathrm{e}}=2.85, p<.0001\right]$. The subjects who viewed the hospital story rated the story and their responses as being more emotional than did the subjects who viewed the garage story $(M \mathrm{~s}=5.6$ and $5.0 \mathrm{vs} .2 .7$ and 2.4 , respectively, when the sign on the 9-point scale was ignored). No other effects were significant.
Memory measures. Figure 1 depicts the three memory measures for physiological arousal across phases. Figure 2 depicts the three memory measures for emotional arousal across phases. The $95 \%$ confidence intervals are plotted around the means. The confidence intervals were calculated using the pooled estimate of the withincondition variance (G. R. Loftus \& Masson, 1994) for each phase. Each phase included the between-subjects variables of physiological and emotional arousal. When viewing both figures, it is clear that memory performance was best for gist, worst for background detail, and intermediate for central detail. In addition, memory performance improved across phases for gist but not for central detail and background detail.

Figure 1 indicates that physiological arousal did not influence any of the memory measures. In contrast, Figure 2 indicates that emotional arousal did influence two of the memory measures. The first panel indicates that gist was not influenced by emotional arousal. The second panel indicates that central detail memory was superior for the hospital story, relative to the garage story, for Phases 1 and 2. These findings replicate, in part, those of Burke et al. (1992), who also found that subjects who viewed the emotional story performed better in Phase 2 , where the arousal manipulation took place. The third panel indicates that background detail memory was superior for the garage story, relative to the hospital story, during Phase 1. Most notable, however, is the superior performance for the subjects who viewed the hospital story in Phase 2.

\section{Discussion}

An examination of these results reveals two interesting findings. First, no effects were found for physiological arousal. Second, although emotional arousal had little impact on gist, it enhanced memory for both central and background detail. It is important to note that memory performance for gist improved across the phases for all groups, probably because of the development of the story line across phases of the slide presentation (i.e., the earlier aspects of the story provide a framework for the later aspects, which are better encoded and remembered).

It should also be noted that the central and background detail memory performance of the subjects in Phase 1 was different for the emotional story, relative to the neutral story. Because the emotional manipulation took place in Phase 2, the story effects in Phase 1 were not expected. One explanation for these effects is that Slide 4 is different in the two conditions. Slide 4 in the emotional story includes the front of a hospital building that occupies almost the entire frame of the slide. Other than cars in the street, the only other details are items such as windows and light poles. In the neutral story, Slide 4 depicts a gas station, with a dark building in the background and a car, a small building, and a pole in the foreground. The contrast between the two slides, in terms of content and composition, is quite clear and could lead to performance dif- 
Gst

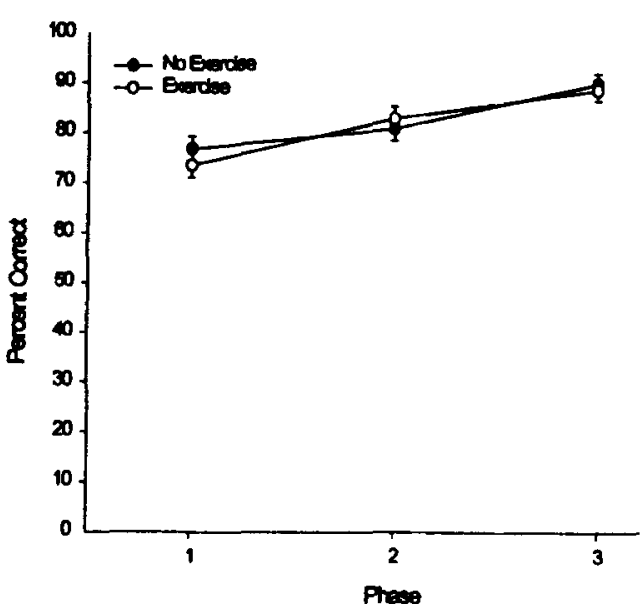

Centra' Detall

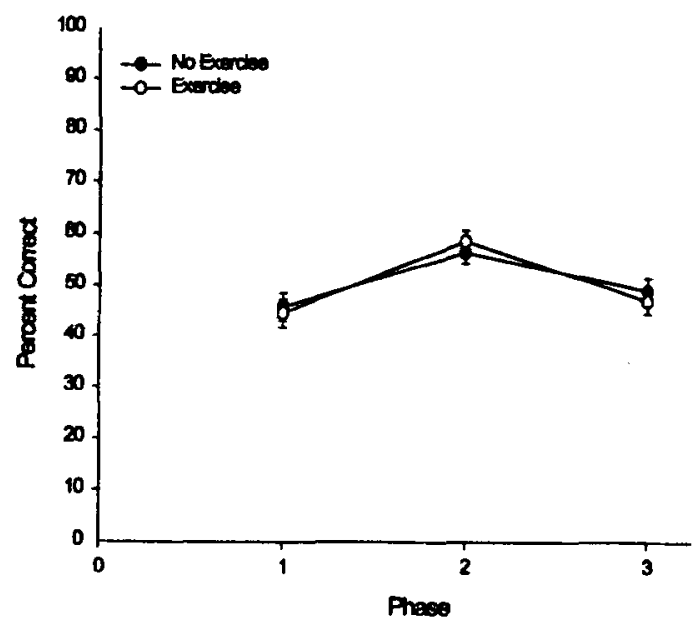

Background Dotail

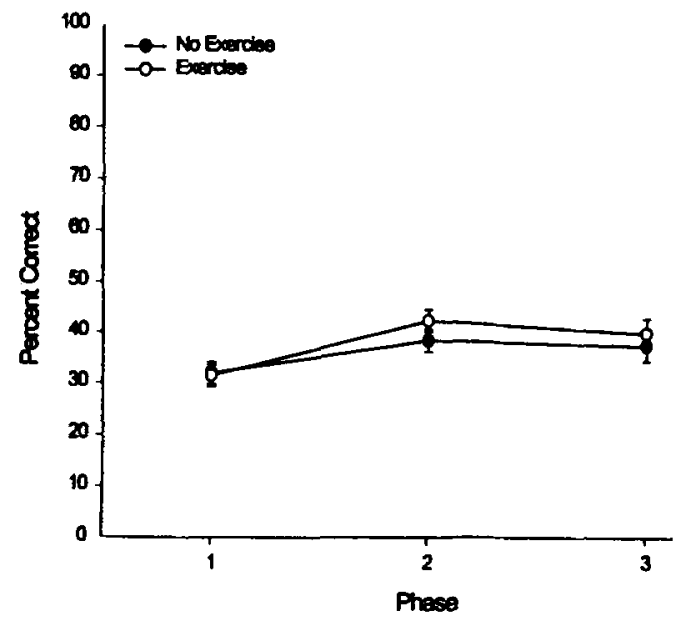

Figure 1. Experiment 1: Memory for gist, central detail, and background detail as a function of phase and physiological arousal.

ferences between the two stories. There is another possible explanation for the memory differences in Slide 4 . However, because this effect is also evident in Experiments 2 and 3, discussion of this issue will be reserved for the General Discussion section. Finally, in contrast to the Heuer and Reisberg (1990) and the Burke et al. (1992) studies, in which heart rates declined for subjects who viewed the emotional story (i.e., the orienting response), we found that heart rates declined for the subjects in both the emotional and the neutral conditions. Although we were not able to support the notion that the hospital version had a physiological impact on the subjects, it is clear from the rating scale data that the subjects who viewed the hospital version perceived this condition as being more emotional than did the subjects who viewed the garage version. This finding is consistent with findings reported by Heuer and Reisberg (1990) and Burke et al.

The most important finding of Experiment 1 was the improvement in memory for background detail when the subjects were exposed to the emotional arousal condition (i.e., the hospital story). This finding was contrary to the Burke et al. (1992) results, in which they found that memory for background detail was superior for the garage story. We partially replicated the Burke et al. experiment in order to determine whether we could obtain the same results as Burke et al. in our laboratory. Results that mimic those of Burke et al. would lend credibility to the notion that the differences in the two experiments were due to the construction of the dependent measure and not to some other extraneous source. The essence of this replication was to use the recognition measure that Burke et al. de- 
Gst

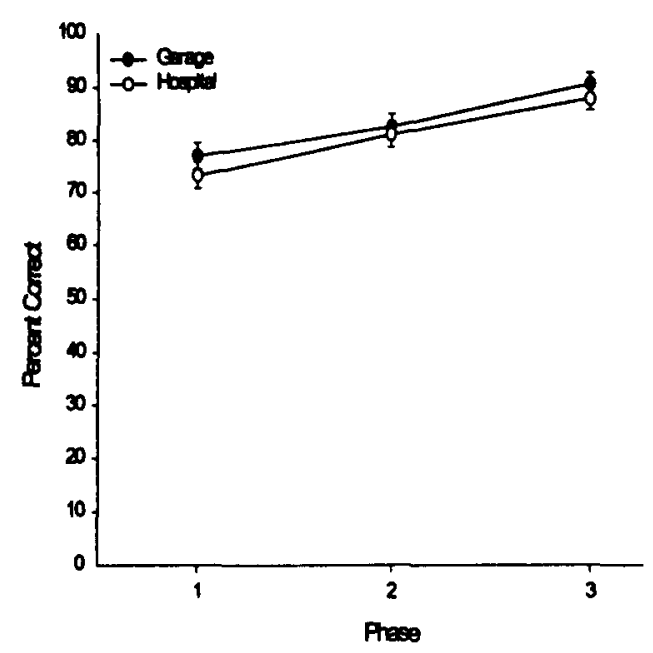

Central Detail

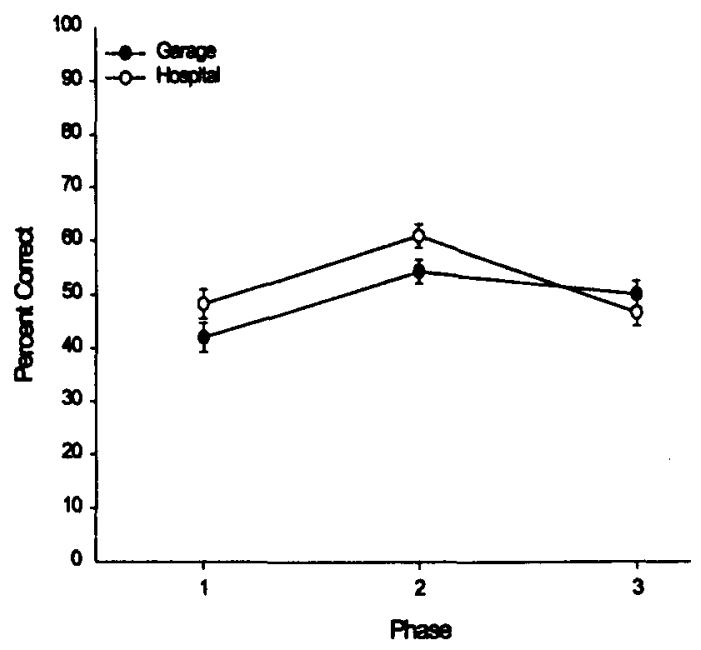

Backgrand Detail

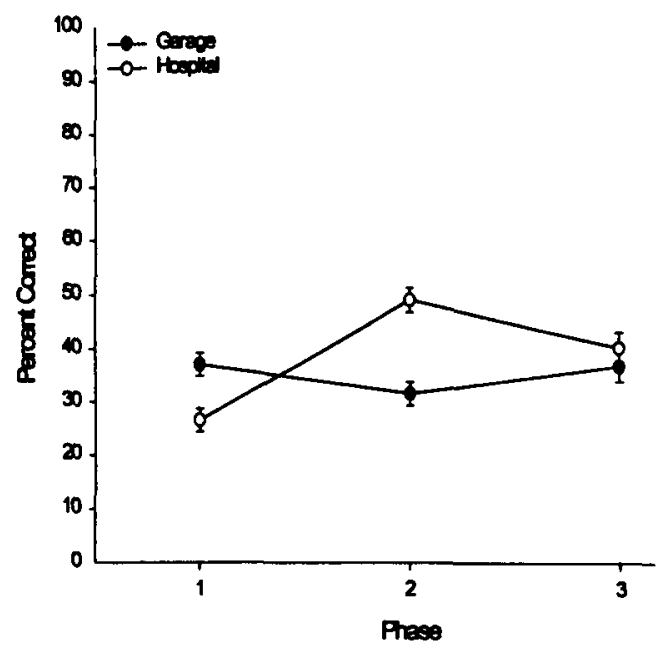

Figure 2. Experiment 1: Memory for gist, central detail, and background detail as a function of phase and emotional arousal.

veloped and used in both of their experiments. Basically, the subjects were tested with the four categories (gist, basic-level visual information, central detail, background detail) that were constructed by Burke et al.

Except for some minor differences, we essentially replicated the Burke et al. (1992) methodology with 40 undergraduate students who were randomly assigned to the two story conditions. The minor differences included the instrument and the location used to measure heart rate (Burke et al. used a CIC speedometer with the earlobe as the source; we used a Polar Favor monitor that was placed around the subject's body at the level of the solar plexus), a chin rest to stabilize head movements (Burke et al. used one, we did not), and the method of administering the memory test (Burke et al. used a computer, we did not).
There was considerable similarity between the Burke et al. results and ours. Of particular importance were the results for central and background detail. In both studies, the major finding was that, during emotional arousal, there was a memory advantage for central detail and a memory disadvantage for background detail. The results were also the same for gist and basic-level visual information, in that both studies reported improvement across phases for gist and a decline across phases for basic-level visual information. The major discrepancy occurred with the heart rate data. We were not able to find evidence supporting the orienting reaction that Burke et al. found. The heart rate measure may be responsible for these differences. Heuer and Reisberg (1990) and Burke et al. used an earlobe photocell to measure opacity of blood flow, 
whereas we used chest electrodes to measure electrical activity of the heart. Measurements using the earlobe photocell can be influenced by body movements and by bright or changing lights, whereas the EKG signal is very strong in the chest area and less susceptible to interference (Heart Rate Monitor Buyer's Guide, 1992). In addition, Léger and Thivierge (1988), in a study that experimentally compared a variety of heart rate monitors with the more conventional ECG, reported high correlations between chest monitor readings and ECG readings and poor correlations between earlobe readings and ECG readings. The authors concluded that chest monitors were stable and valid, whereas earlobe measures have problems with stability and validity. Although we did not find the orienting response, it is important to note that the rating scale data in the replication indicated that the subjects in the emotional story condition perceived the story as being more arousing than did the subjects in the neutral story condition.

\section{EXPERIMENT 2}

The major purpose of Experiment 2 was to determine the influence of physiological and emotional arousal on cued recall for central and background detail of an event. The major difference between Experiments 1 and 2 concerns the nature of the memory task. In Experiment 1 , memory was measured with a recognition task, whereas in Experiment 2, memory was measured with a cued recall task. The major question, of course, concerns the extent to which the findings reported in Experiment 1 are repeatable for a cued recall task. In other words, do the findings from Experiment 1 have any generality?

Cued recall was chosen because the number and distribution of test items across categories of information (gist, central detail, and background detail) and phases in the recognition task could be essentially maintained in a cued recall task, thus allowing for more valid comparisons between the two tasks. Although there is considerable discussion in the cognitive literature concerning the role of familiarity and retrieval processes in recognition and recall tasks (see Wilhite \& Payne, 1992, for a brief review), we know of no a priori reason for assuming that these tasks will be differentially sensitive to memory for central and background detail. However, in a study concerned with memory for traumatic events, Christianson and E. F. Loftus (1987) used a recall task to assess thematic memory and a recognition task to assess details. These authors reported that memory for the thematic event was superior and memory for detail was inferior, relative to a neutral condition. These data suggest that, in our cued recall study, memory for gist should be superior for the hospital story, relative to the garage story.

\section{Method}

Subjects. Eighty undergraduate students from Central Michigan University were recruited from introductory psychology classes. The subjects were randomly assigned to the four treatment conditions, with the restriction that an equal number of males and females be placed in each condition. Checking subject files indicated that 1 subject had served in Experiment 1. Her data were discarded, leaving 19 subjects in the physiological arousal, neutral story condition.

Materials and Apparatus. The stimuli (slides and narratives), emotional rating scales questionnaire, and apparatus (slide projector and heart rate monitor) were the same as those used in Experiment 1 . The subjects were also tested in the same environment, with the stimuli and apparatus being arranged in the same manner.

Content validity of the cued recall test. The questions from the recognition test used in Experiment 1 were converted to cued recall questions. For example, in the recognition test, the question was asked, "What is the color of the door?" The four alternatives were blue, brown, green, and black. The cued recall question was phrased "The color of the door is ___." The correct answer was blue. The procedure for establishing content validity was similar to the procedure outlined in Experiment 1 . The overall content validity coefficient was 89.57 . Fifty-eight percent of the items had a coefficient of 1.00 , and $42 \%$ had a coefficient of .75 . Finally, there were a few items, particularly background detail, for which the possibility existed for multiple correct answers. In order to remedy this problem, 3 individuals (the second and third authors of this paper and a graduate student familiar with the study) viewed each slide and listed all the possible answers that could be correct for each cued recall question. These answers were scored as correct for those subjects who responded with these answers.

Design and Procedure. The design was a 2 (physiological arousal) $\times 2$ (story type) $\times 3$ (phase) $\times 3$ (category of information) factorial, with the first two as between-subjects variables and the last two as within-subjects variables. Each category of information was analyzed separately, using percent correct cued recall as the dependent measure. The emotionality rating scale and heart rates measures were used to assess emotional and physiological arousal. The subjects were tested, using the procedure outlined in Experiment 1 .

\section{Results}

Heart rate data. Initial baseline heart rates ranged from 54 to $115 \mathrm{bpm}$. The 2 (physiological arousal) $\times 2$ (story) ANOVA revealed a main effect of story $[F(1,75)$ $\left.=4.60, M S_{\mathrm{e}}=164.16, p<.04\right]$, indicating that the subjects who later viewed the hospital story $(M=84.72)$ initially exhibited higher heart rates than the subjects who later viewed the garage story $(M=78.51)$. An analysis of the second baseline measure indicated that heart rates were higher $\left[F(1,75)=462.48, M S_{\mathrm{e}}=177.84, p<.0001\right]$ for the subjects who ran in place $(M=142.20)$ than for the subjects who did not run in place $(M=78.65)$. No other significant effects were noted. It is clear from the heart rate analysis that initial heart rates are confounded with story conditions. It is possible that the subjects with higher initial heart rates are more sensitive to the content of the stories than are the subjects with the lower initial heart rates, which, in turn, could account for any reported memory differences in the stories. Although this confound was not found for the second baseline heart rates (note that the means were 80.30 and 77.00 for the subjects who were not physiologically aroused [i.e., the subjects who did not run in place] and who viewed the hospital story or the garage story, respectively), it is still possible that the memory data are contaminated. Therefore, all subsequent analyses concerning the rating scales and memory measures were conducted with an analysis of covariance (ANCOVA), with initial heart rate as the 
covariate. Although ANCOVAs will be reported here, ANOVAs were also conducted on these measures. Only two differences were noted. First, in the ANOVA analyses, main effects of phase were found for gist and central detail (but not background detail), indicating that memory performance improved across phases. In the ANCOVA analyses, a main effect of phase was found for background detail (again, memory performance improved across phases) but not for gist and central detail. Second, in the ANOVA analysis of background detail, a main effect for physiological arousal was found (memory performance was better for the subjects who ran in place, relative to the subjects who did not run in place). In the ANCOVA analysis, no main effect for physiological arousal was found.

As in Experiment 1, the second of the three measures of heart rate for each slide was used to calculate mean group heart rates. Heart rates declined across the phases $\left[F(2,150)=229.95, M S_{\mathrm{e}}=22.08, p<.0001\right]$, and the physiological arousal $\times$ phase interaction $[F(2,150)=$ $139.95, p<.0001]$ indicated that the heart rates of the subjects who ran in place started much higher and dropped much faster than did those of the subjects who did not run in place.

Finally, for the subjects who did not run in place, the lowest heart rate measure for each slide was used to calculate mean heart rates. This was the measure used by Burke et al. (1992), which led to the finding that heart rates declined during the hospital story, relative to the garage story. The 2 (story) $\times 12$ (slides) ANOVA revealed only an effect of slides $\left[F(11,418)=15.94, M S_{\mathrm{e}}=9.81\right.$, $p<.0001]$, which indicated that heart rates declined for both groups across slides, with the greatest decline occurring during the first three slides.

Rating scales. The 2 (physiological arousal) $\times 2$ (story) ANCOVA of the rating scale data for the emotionality of the slide presentation revealed significant effects for story $\left[F(1,74)=48.07, M S_{\mathrm{e}}=3.16, p<.0001\right]$ and for the physiological arousal $\times$ story interaction $[F(1,74)=8.12, p<.006]$. The main effect indicated that the hospital story $(M=5.48)$ was perceived as being more emotional than the garage story $(M=2.68)$. However, this effect was moderated by the interaction, which indicated that, for those subjects who were physiologically aroused, the difference between the hospital story condition $(M=6.30)$ and the garage story condition $(M=$ 2.37) was greater than for those subjects who were not physiologically aroused (hospital and garage story means were 4.65 and 3.00 , respectively).

The 2 (physiological arousal) $\times 2$ (story) ANCOVA of the subjects' responses to the slide presentation revealed significant effects for physiological arousal $\left[F(1,74)=5.02, M S_{\mathrm{e}}=2.55, p<.03\right]$, story $[F(1,74)=$ $55.70, p<.0001]$, and the physiological arousal $\times$ story interaction $[F(1,74)=8.44, p<.005]$. The physiological arousal effect indicated that the physiologically aroused subjects responded more emotionally than did the nonphysiologically aroused subjects. The story effect indicated that the subjects responded more emotionally to the hospital story than to the garage story. These effects were moderated by the interaction, which indicated that, when the subjects were both physiologically and emotionally aroused, their perceived emotional reactions $(M=6.00)$ were greater, as compared with the remaining three treatment combinations (the means for the hospital nonarousal, garage arousal, and garage nonarousal groups were $4.20,2.26$, and 2.55 , respectively). This finding is consistent with the interaction concerning the perceived emotionality of the slide presentation.

Memory measures. Figure 3 depicts the three memory measures for physiological arousal across phases. Figure 4 depicts the three memory measures for emotional arousal across phases. The $95 \%$ confidence intervals are plotted around the means, using the same approach as that used in Experiment 1. It is clear from viewing both figures that memory performance was best for gist, worst for background detail, and intermediate for central detail. It is also evident that gist improved across phases. Both of these observations are consistent with the findings in Experiment 1.

Figure 3 indicates that physiological arousal had little impact on memory. Only in the third panel did physiological arousal have any impact, and this effect indicated that exercise improved memory for background detail during Phase 1. In contrast, Figure 4 indicates that emotional arousal produced numerous effects on memory. The gist panel indicates that memory performance was superior for the garage story, relative to the hospital story, for Phases 2 and 3. More important, however, are the findings for central and background detail. The central detail panel indicates that memory performance was superior for the hospital story, relative to the garage story, during Phase 2 . The background detail panel also indicates that memory was superior for the hospital story, relative to the garage story, during Phase 2 . In addition, however, the background detail panel indicates that memory was superior for the garage story, relative to the hospital story, during Phase 3. Finally, it should be noted that background detail memory performance was similar in the two story conditions during Phase 1 . This finding is contrary to that in Experiment 1, where the garage story was superior to the hospital story during Phase 1 .

\section{Discussion}

The purpose of Experiment 2 was to determine whether the findings obtained in Experiment 1, using a recognition task, could be confirmed in Experiment 2, using a cued recall task.

In Experiment 1, no group differences were found for the initial baseline heart rate data, whereas in Experiment 2 , the subjects who would later view the hospital story had higher heart rates than did the subjects who would later view the garage story. These effects were not found for the second baseline measure. A comparison of the initial and second baseline heart rate means is informative. For the subjects who would later run in place, the 
Gist

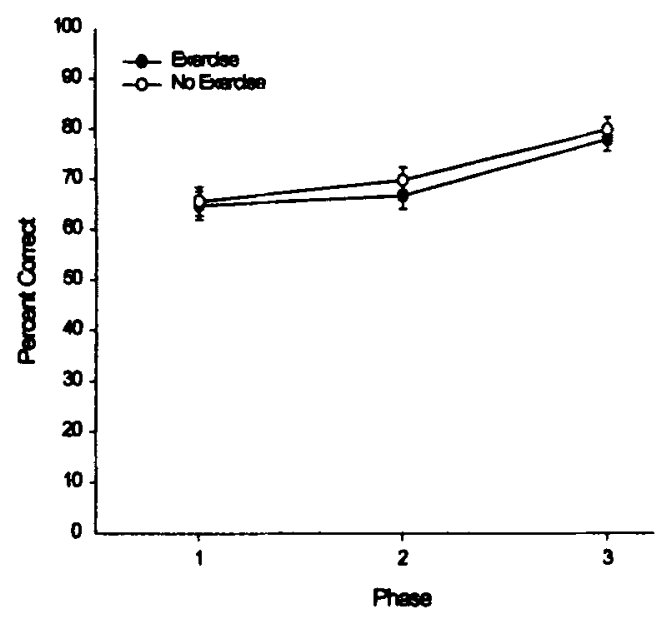

Central Detail

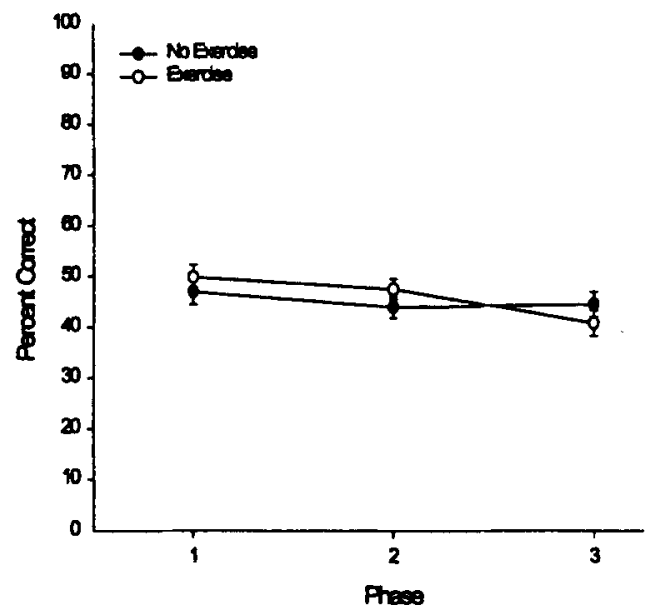

Background Detail

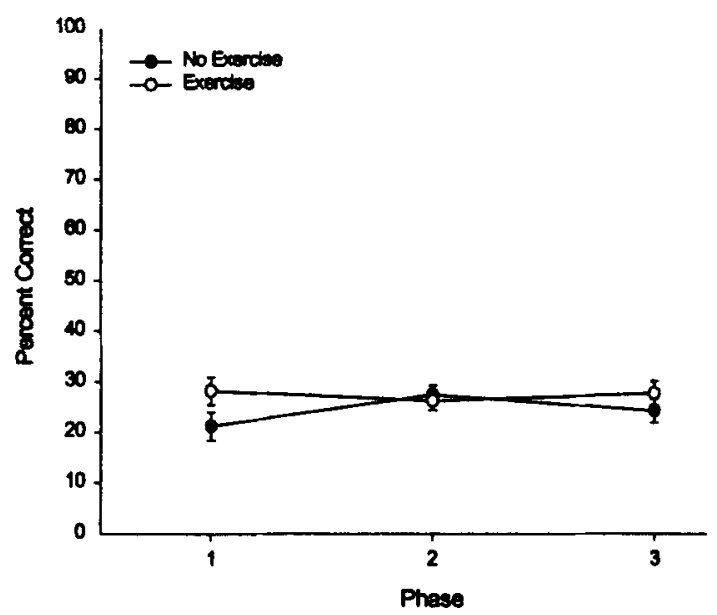

Figure 3. Experiment 2: Memory for gist, central detail, and background detail as a function of phase and physiological arousal.

initial baseline means for the hospital and garage stories were 85.75 and 77.54 , respectively. After running in place (i.e., the second baseline measure), the means for the hospital and garage stories for these same subjects were 142.45 and 143.95 , respectively. For the subjects who would not later run in place, the initial baseline means for the hospital and garage stories were 83.75 and 79.55 , respectively. The second baseline measures for these two groups were 80.30 and 77.00 , respectively. Although these heart rate differences are not substantial, ANCOVAs were used in all subsequent rating scale and memory data to rule out the possibility that initial heart rates were influencing these measures. The heart rate data recorded during the slide presentation was similar for Experiments 1 and 2 . In both cases, heart rate declined at a faster rate for the subjects who ran in place, relative to the subjects who did not. Furthermore, heart rate declined at the same rate across phases for both story conditions. This latter finding did not support the Burke et al. (1992) data concerning an orienting response.

There were some notable differences between Experiments 1 and 2 concerning the emotionality rating scale data. In Experiment 1, only story effects were found, whereas in Experiment 2, there was, in addition to story effects, a physiological arousal $\times$ story interaction. The interaction indicated that the ratings were most pronounced for those subjects who ran in place and viewed the hospital story. Although we do not have a plausible explanation for these discrepancies, it is important to remember that, in both experiments, the hospital story was rated as being more emotional than was the neutral story. It is also interesting to note, as will be discussed later, that 
Gst

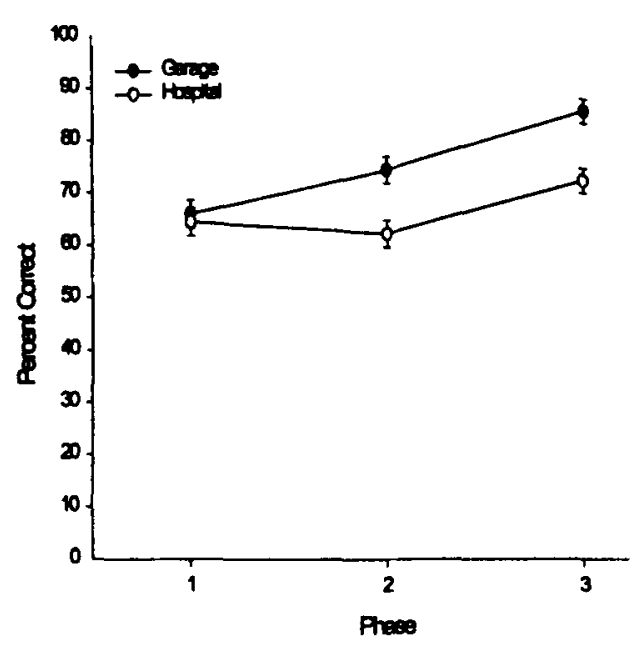

Central Detail

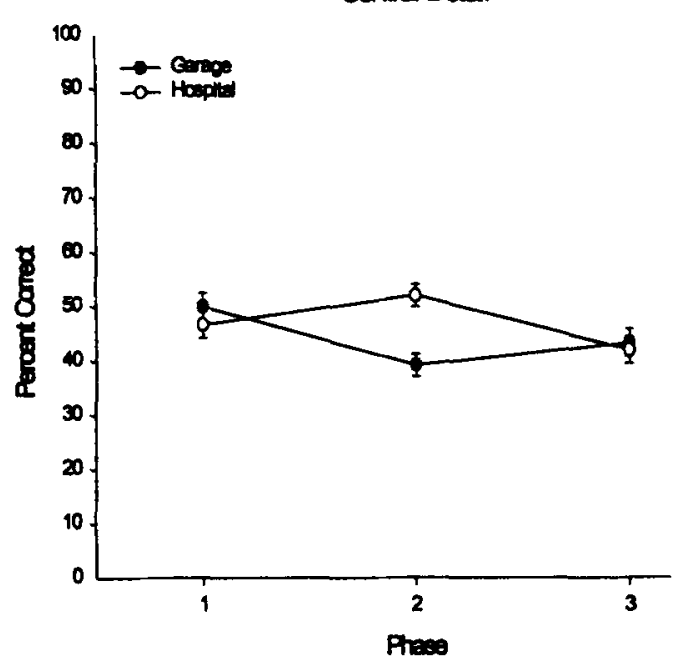

Badgrand Datail

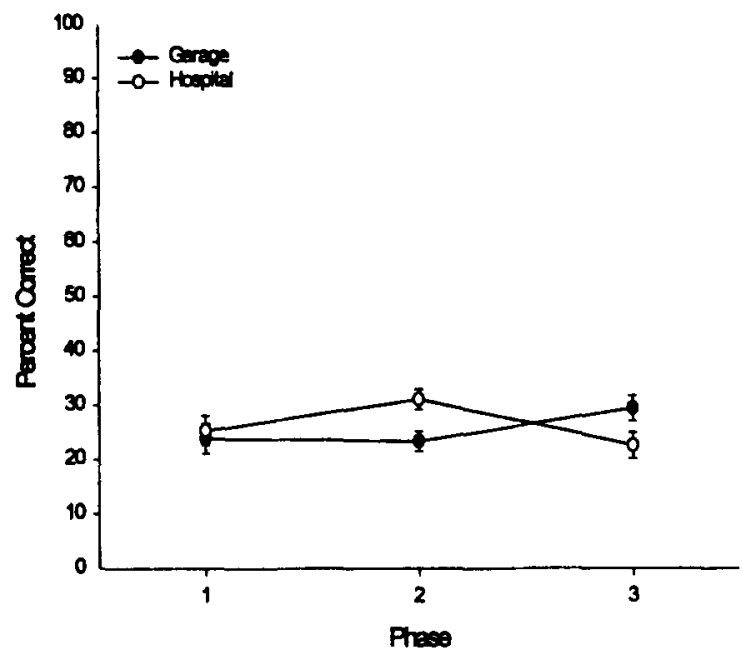

Figure 4. Experiment 2: Memory for gist, central detail, and background detail as a function of phase and emotional arousal.

although physiological arousal influenced the rating scale measures, it did not influence the memory measures.

Some differences were also noted when the gist data were compared in Experiments 1 and 2. In Experiment 1, memory improved across phases regardless of the story condition, whereas in Experiment 2 memory for the neutral story was superior to the emotional story for Phases 2 and 3. These data, therefore, do not support the Christianson and E. F. Loftus (1987) view that thematic memory is superior for traumatic events. However, it is puzzling not to find positive memory effects for thematic materials. It may be the case that the test items' difficulty differed for the two conditions. There were also some differences concerning the findings for background detail in Experiments 1 and 2 (i.e., neutral information was remembered better than emotional information during Phase 1 in Ex- periment 1 but not in Experiment 2, and neutral information was remembered better than emotional information during Phase 3 in Experiment 2 but not in Experiment 1).

However, in comparing the two experiments, the most important finding concerned the relationship between emotional arousal and memory. In both experiments, the emotional story was remembered better than the neutral story during Phase 2 . In other words, for recognition and cued recall, there is a distinct memory advantage for both central and background detail during emotional arousal.

\section{EXPERIMENT 3}

The purpose of Experiment 3 was to determine whether the same effects reported in Experiments 1 and 2 could be obtained when physiological arousal was 
maintained during encoding. In Experiments 1 and 2, physiological arousal was induced prior to encoding but allowed to decline during the viewing of the slides. It is possible that variable and/or declining arousal levels may have different effects than stable arousal levels. In other words, the null effects for physiological arousal reported in Experiments 1 and 2 may have resulted from changing arousal levels during the encoding interval. In Experiment 3, physiological arousal was maintained during the encoding interval by stationary biking. Three between-subjects levels of physiological arousal were factorially combined with two between-subjects levels of emotional arousal. Memory (gist, central detail, and background detail) was assessed, using the recognition test from Experiment 1.

\section{Method}

Subjects. One hundred and twenty-six students were recruited from introductory psychology courses. The subjects were randomly assigned to the six treatment conditions, with about the same number of women and men in each condition. Data from 1 male were excluded because of a recording error.

Materials and Apparatus. The stimuli (slides and narratives), emotional rating scales, questionnaire, slide projector, heart rate monitor, and testing environment were the same as those used in Experiments 1 and 2. A Wesio Aero 800 Variable Resistance stationary bicycle was used to induce physiological arousal. The bike tension was set on the lowest resistance setting for all the subjects. The handle bars were removed to avoid distraction during the slide presentation. The subjects were seated on the bike at a distance of approximately $8 \mathrm{ft}$ from the projection wall. Heart rates were monitored with the Polar Favor heart rate monitor.

Design. The design was a 3 (physiological arousal) $\times 2$ (story) $\times$ 3 (phase) $\times 3$ (category of information) factorial, with the first two variables being between-subjects variables and the latter two being within-subjects variables. Each category of information was analyzed separately, using percent correct recognition responses as the dependent measure.

Procedure. The subjects were tested, using a procedure that was similar to the one outlined in Experiment 1. The major exception occurred with respect to the physiological arousal variable. Physiological arousal was manipulated through stationary bike riding. The three levels of physiological arousal were no exercise (the subjects sat on the bike without pedaling), low exercise (the subjects pedald at a rate sufficient to maintain a $10 \%-20 \%$ increase in heart rate over baseline), and moderate exercise (the subjects pedaled at a rate sufficient to maintain a $40 \%-50 \%$ increase in heart rate over baseline)

The subjects were instructed to sit on the bike (the height of the bike seat was adjusted on the basis of the subject's comfort level) and relax. The experimenter then waited for about $2 \mathrm{~min}$ for the heart rate to stabilize. The heart rate at the end of this period was recorded as Baseline 1. The subjects in the no-exercise condition were merely instructed to sit on the bike. The subjects in the lowand moderate-exercise conditions were instructed to begin to pedal and to increase their rate until criterion was achieved. They were then instructed to maintain this level. Because of a noticeable increase in the noise level produced by riding the bike at the moderate level, the volume of the tape player was adjusted to a higher level for the subjects in this condition. Once the subjects were within the prescribed range, they were asked if they could maintain that speed without concentrating on it during the slide presentation (all the subjects answered affirmatively to this question). After the affirmative answer, the experimenter started the slide presentation and tape recorder and recorded the subject's heart rate $2 \mathrm{sec}$ after each slide appeared. When the slide presentation was completed, the experimenter instructed the subject to stop pedaling, step off the bike, be seated at a desk, and complete the emotionality rating scales. After completion of this task and about $5 \mathrm{~min}$ had passed, heart rate was again recorded (Baseline 2). The heart rate monitor was then removed, and the subjects were instructed to complete the filler task and the recognition task. Finally, the subjects were asked if they felt that pedaling the bicycle had been a problem for them while they were viewing the slides. This question was added after the experiment began, and, therefore, not all of the subjects were exposed to this question.

\section{Results}

Reported interference from pedaling. Of the 31 subjects in the no-exercise condition who were asked, only 1 subject reported that sitting on the bike interfered with viewing the slides. Of the 23 subjects in the lowexercise condition who were asked, only 3 subjects reported any interference with viewing the slides while riding the bike. Of the 31 subjects in the moderate exercise condition who were asked, 12 subjects reported some interference.

Heart rate data. Baseline 1 heart rates ranged from 53 to $112 \mathrm{bpm}$. The 3 (physiological arousal) $\times 2$ (story) ANOVA did not reveal any significant effects. Baseline 2 (taken about $5 \mathrm{~min}$ after the completion of the exercise conditions) heart rates ranged from 49 to $128 \mathrm{bpm}$. The 3 (physiological arousal) $\times 2$ (story) ANOVA did not reveal any significant effects. The measures of heart rate for each slide were summed and averaged for each treatment combination. The 3 (physiological arousal) $\times 2$ (story) $\times 3$ (phase) mixed effects ANOVA revealed significant effects for physiological arousal $[F(2,120)=52.06$, $\left.M S_{\mathrm{e}}=888.45, p<.0001\right]$ and for the phase $\times$ physiological arousal interaction $\left[F(4,240)=3.68, M S_{\mathrm{e}}=7.10\right.$, $p<.006]$. The means for the three physiological arousal conditions were 83.62 (no exercise), 97.42 (low exercise), and 120.43 (moderate exercise). The interaction is largely a result of an increase of less than one beat in heart rate from Phase 1 through Phase 3 in the moderate condition, whereas there was about a one beat decrease across phases for the low condition. The proportion of variance accounted for by this effect is small $\left(\eta^{2}=.05\right)$.

As in the previous experiments, an analysis was conducted on the heart rates for each slide for the subjects who did not engage in any physical exercise. The 2 (story) $\times 12$ (slides) ANOVA revealed only a significant effect for slides $\left[F(11,451)=5.62, M S_{\mathrm{e}}=11.68, p<.0001\right]$. All of the mean heart rates were in the $82-83$ range, with the exception of the mean heart rate for the first slide, which was 86 . It should be noted that, in the present study, heart rates were those taken after the onset of $2 \mathrm{sec}$ for each slide, whereas, in the Burke et al. (1992) study, the lowest heart rate of three recordings for each slide was taken as the measure.

Rating scales. Analyses of the emotionality rating scale data using 3 (physiological arousal) $\times 2$ (story) ANOVAs revealed significant effects of story for both 
Gist

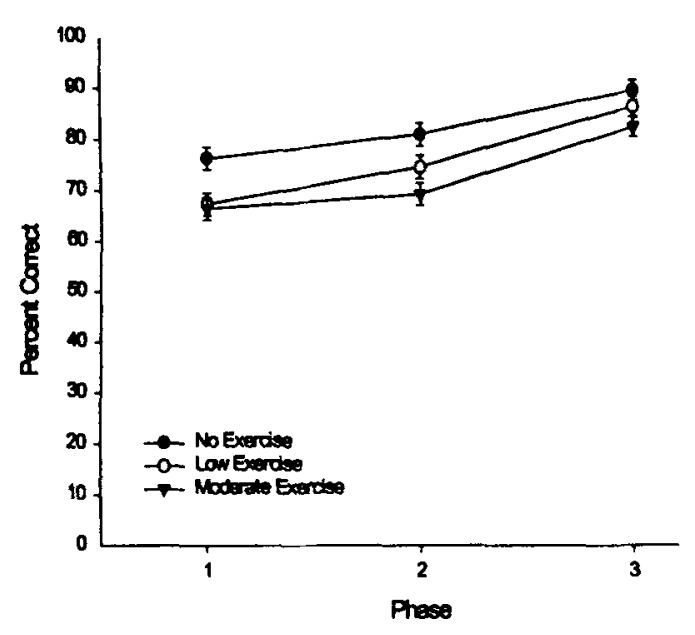

Central Detai

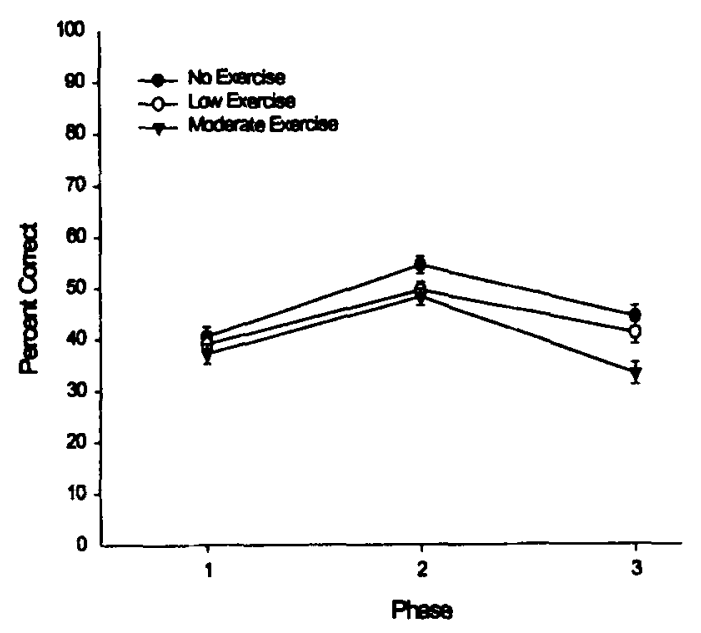

Bedgrand Detal

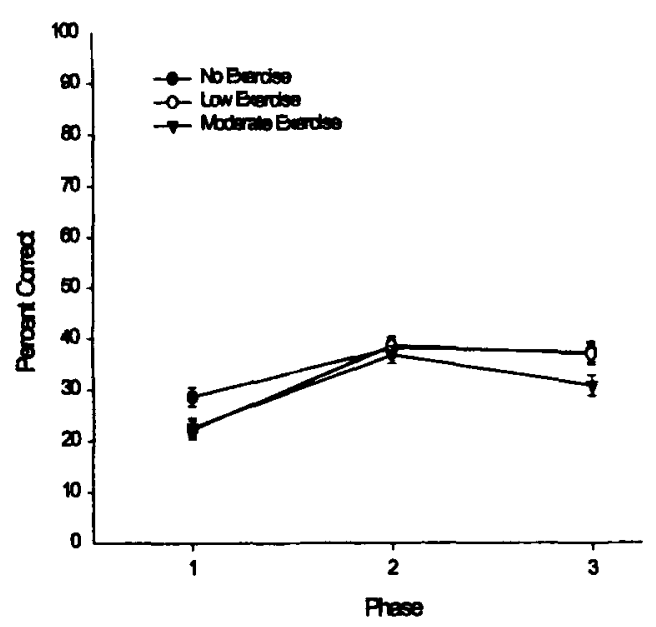

Figure 5. Experiment 3: Memory for gist, central detail, and background detail as a function of phase and physiological arousal.

the emotionality of the slide presentation $[F(1,120)=$ $\left.56.85, M S_{\mathrm{e}}=3.89, p<.001\right]$ and the subject's response $\left[F(1,120)=25.33, M S_{\mathrm{e}}=4.10, p<.001\right]$. The subjects who viewed the hospital story rated the story $(M=5.5)$ and their responses $(M=4.6)$ as being more emotional than did the subjects who saw the garage story (both means were about 2.8 ). No other significant effects were noted.

Memory measures. Figure 5 depicts the three memory measures for physiological arousal across phases. Figure 6 depicts the three memory measures for emotional arousal across phases. The $95 \%$ confidence intervals are plotted around the means, using the same procedure as that used in the previous two experiments. When viewing both figures, memory performance is best for gist, worst for background detail, and intermediate for central detail. Also evident for gist in both figures is the increase in memory performance across phases. These finding are consistent with the first two experiments. Figure 5 indicates that three memory measures were influenced by physiological arousal. In general, the moderate exercise condition lead to decrements in all three memory measures, relative to the no-exercise condition. In contrast, there were few differences between the no-exercise and low-exercise conditions.

Figure 6 indicates that emotional arousal influenced all three memory measures. The gist panel indicates that, during Phase 1, memory was superior for the garage story, relative to the hospital story. The central detail panel indicates that, during Phase 2 , memory for the hospital story was superior to that for the garage story, and during Phase 3, the relationship was reversed. The background detail panel indicates that, during Phase 2, memory for the hospital story was superior to that for the garage story, and during Phases 1 and 3, the relationship was reversed. 
Gst

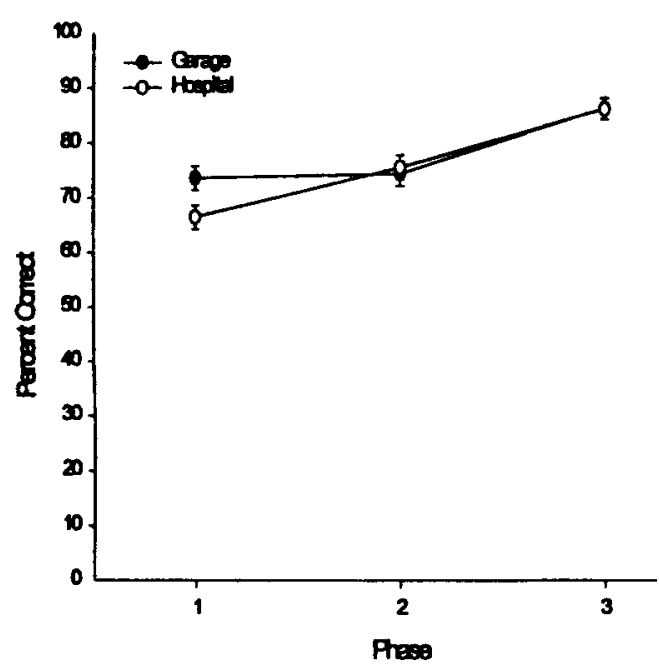

Cantral Detail

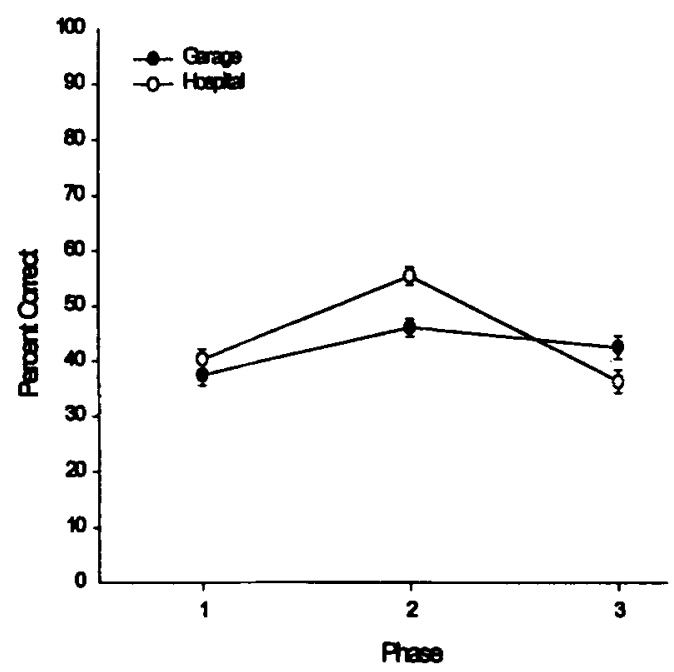

\section{Backgrand Datail}

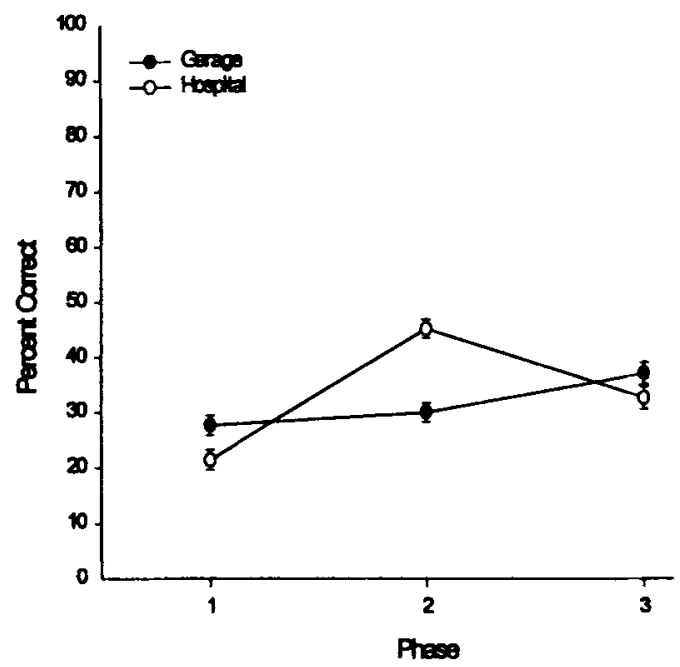

Figure 6. Experiment 3: Memory for gist, central detail, and background detail as a function of phase and emotional arousal.

\section{Discussion}

The purpose of Experiment 3 was to determine whether stable physiological arousal levels would produce the same memory effects as those that were reported in Experiments 1 and 2, where arousal levels were declining during the encoding period. Our most important finding indicated that, during Phase 2, memory for central and background detail was superior for the hospital story, relative to the garage story. This finding is consistent with the findings in the first two experiments. However, in contrast to Experiments 1 and 2, where physiological arousal did not influence memory, the data from Experiment 3 indicated that physiological arousal decreased memory for gist, central detail, and background detail.
There are two important points regarding this finding. First, although the memory means decreased as arousal levels increased, only the comparisons between the noexercise and moderate exercise conditions led to consistent differences. In other words, memory in the low-exercise condition, where subjects were $10 \%-20 \%$ above baseline rate, was similar to that in the no-exercise condition. The decrease in memory for the moderate exercise condition may be due to the increased attentional demands placed on the subjects when they were required to maintain heart rates at $40 \%-50 \%$ above baseline. In support of this latter view, $39 \%$ of the subjects in the moderate exercise condition, relative to the no-exercise and lowexercise condition, for which the percents were 3 and 13 , 
respectively, did report interference from pedaling. This latter view fits nicely with a processing resources explanation (Wickens, 1984). The subjects were required to perform several tasks concurrently (i.e., pedaling, maintaining a fixed pedaling rate, and processing the visual and auditory information from the slides). When there is no exercise or low exercise, the available resources are sufficient to maintain time-sharing efficiency, whereas, in the moderate exercise condition, the demand exceeds the supply, and time-sharing efficiency declines. Basically, the subjects devote their attention to the pedaling, to the detriment of processing the to-be-remembered stimuli. The second important point is that, in general, physiological arousal did not differentially affect memory for phase or story. In other words, physiological arousal simply depressed memory performance for gist, central detail, and background detail.

Finally, it is important to compare the results from Experiments 1 and 3, because both experiments measured memory, using a recognition task. Although Figures 2 and 6 indicate some differences, it is clear that the relationships for gist, central detail, and background detail are very similar for both experiments.

\section{GENERAL DISCUSSION}

\section{Physiological Arousal}

A consistent finding for Experiments 1 and 2 was that memory performance was unaffected by physiological arousal. Furthermore, Experiment 3 indicated that memory performance was not affected when the subjects exercised at $10 \%-20 \%$ above their baseline heart rates. Only when the subjects were required to exercise at $40 \%-50 \%$ above their baseline heart rates were effects noted, and these effects were negative (i.e., exercise led to memory decrements). We believe that the decrement is a function of the demands of the various tasks exceeding the processing resources - that is, an attentional explanation. Furthermore, it is important to note that the memory decline was evident for all three measures of memory. In other words, gist, central detail, and background detail were all adversely affected by the exercise, suggesting that the reduction in resources allocated to memory was spread across the array of to-be-remembered information. That is, the subjects did not reallocate resources so that, for example, memory for central detail was maintained, whereas memory for background detail suffered.

On the basis of our studies, what can we conclude about the relationship between physiological arousal and memory? We conclude that physiological arousal does not enhance memory for gist or detail. Is it possible that the null effects may be due to the misattribution of arousal (Schachter \& Singer, 1962; Sinclair, Hoffman, Mark, Martin, \& Pickering, 1994)? In other words, the subjects in the physiological arousal conditions were well aware of the source of their arousal (i.e., the exercise) and, therefore, may have attributed their arousal to the exercise rather than to the story conditions. If the subjects at- tributed their actual physiological arousal to the story conditions, memory for the stories may have improved. On the basis of our design, we cannot rule out this possibility, and, therefore, additional research will be required to address this issue. However, it is difficult to understand how an attribution explanation can account for the decrease in memory in the moderate exercise condition in Experiment 3. Regardless, it is clear that physiological arousal per se does not produce any effects on memory.

The possibility also exists that physiological arousal may have delayed effects. For example, Christianson (1992a), in his literature review, concluded that there are numerous studies indicating that high-arousal events are remembered better than low-arousal events when testing is delayed but not when testing is immediate. However, these studies fall within the domain of emotional arousal rather than physiological arousal. We think the answer to the question is a moot one. It is possible that physiological arousal may enhance memory if testing is delayed. It is also possible that physiological arousal may interact with emotional arousal if testing is delayed. Other possibilities exist, and empirical studies will be needed to answer this question. The failure to find any appreciable memory effects for physiological arousal in our experiments suggests that the source of arousal is an important determinant of an event's memorability. In other words, in order for arousal to have any impact on memory, it must be relevant to the to-be-remembered event; merely arousing someone will not suffice. Therefore, these data favor a multistate model (Christianson, 1992a; Lacey, 1967; Neiss, 1988a, 1988b) over a unitary model (Humphreys \& Revelle, 1984; Revelle \& D. A. Loftus, 1992) of arousal.

\section{Emotional Arousal}

Emotional arousal led to memory enhancement for both central and background detail. These findings were consistent across Experiments 1 (recognition), 2 (cued recall), and 3 (recognition). Furthermore, the notion that these effects were due to the way in which the dependent variable was constructed (and not to some other extraneous source) was strengthened by our ability to confirm the findings of Burke et al. (1992) with our replication of their study.

\section{Methodological Concerns}

Central and background detail. The conclusion that emotional arousal enhanced memory for central and background detail is surprising because, with one exception (Heuer \& Reisberg, 1990), laboratory studies (see Christianson, 1992a, for a review) have supported the notion that emotional arousal increases memory for central detail and decreases memory for background detail. However, in only a few of these studies were subjects' memories for the events systematically and extensively tested. Without this requirement, as well as without establishing sufficient content validities for the test items, it would not be advisable to base a conclusion on data 
from these studies. It is therefore important to examine the Heuer and Reisberg (1990) and the Burke et al. (1992) studies, because there were serious attempts in these studies to meet both of these requirements.

Before we can compare the findings of Heuer and Reisberg (1990) and Burke et al. (1992) with ours, it is first necessary to understand how central and background detail were treated in the Heuer and Reisberg (1990) and Burke et al. studies. The to-be-remembered materials were the same in both of their studies; they were simply placed in different categories. In the Heuer and Reisberg (1990) study, the to-be-remembered material was categorized into central detail and background detail; in the Burke et al. study, central detail was further divided into gist and basic-level visual information, and background detail was further divided into central detail and background detail. It is appropriate, therefore, to compare the central and background detail findings of our studies with those of Burke et al., as the definitions of central and background detail were the same for these studies. However, some of the to-be-remembered items differed between the two studies. In our studies, using the original items that were developed by Heuer and Reisberg (1990) and modified by Burke et al., we were not able to obtain content validity coefficients greater than .35 . Therefore, test items were modified, added, or deleted until the overall validity coefficients were in the $.80 \mathrm{~s}$.

It is clear that, when the comparisons are made between the two studies, the results are consistent for central detail (emotional arousal improved memory) and inconsistent for background detail (Burke et al,, 1992, reported that memory declined with emotional arousal, whereas we found that memory improved with emotional arousal). How can we account for this discrepancy? Two possibilities come to mind. One possibility is based on the categorization of test items. In our study, the items were categorized by four graduate students who were not familiar with the study. As was stated earlier, these individuals were not able to consistently agree with Burke's categorization. In contrast, in the Burke et al. study, the first two authors independently categorized the items. Burke et al. reported that $95 \%$ accuracy was achieved, with the third author settling any disputes. In other words, familiarity with the study may account for the contradictory findings. The second possibility is based on the sampling of the content of the slides. Number and distribution of central detail test items were similar for both studies (in the Burke et al. study, there were 29 items for the neutral version and 31 items for the emotional arousal version; in our study, there were 31 items for the neutral version and 29 items for the emotional arousal version). In contrast, number and distribution of background detail test items were substantially different. In the Burke et al. study, there were 51 items for the neutral version and 48 items for the emotional arousal version. In our study, there were 30 items for the neutral version and 28 items for the emotional arousal version. The smaller number of background test items in our study is largely due to the failure to obtain sufficient content validity coefficients for some of the background detail items that were in the Burke et al. study. These items were discarded in our study.

We are also concerned with the consistency of the findings for central and background detail in the Heuer and Reisberg (1990) and Burke et al. (1992) studies. One would expect that memory performance would be similar if the central and background detail categories in the Burke et al. study were recombined into background detail and compared with the background detail data in the Heuer and Reisberg (1990) study. In the Burke et al. study, one can roughly estimate the recombined values by examining Figures 2-4 (Experiments 1 and 2 for the immediate testing conditions only) in their paper. When the approximate values are derived from these figures, there is only a slight absolute difference (about $3 \%$ ) favoring the emotional arousal condition. In other words, the emotional story advantage found in the Heuer and Reisberg (1990) study for background detail is not that evident in the Burke et al study. Which study should one believe? The Burke et al. findings appear to be reliable, in that we were able to confirm their findings with our replication. However, in our view, this study poses serious interpretative difficulties, because it is not clear as to what constitutes central and background detail. Overall, at this juncture, we are more likely to believe that our findings provide more clarity than the Burke et al. and Heuer and Reisberg (1990) findings, for two main reasons. First, we were able to establish test item content validities for central and background detail for both the recognition and the cued recall studies. Second, we were able to establish the same effects for recognition and cued recall. In other words, the effects possess some generality.

Arousal $\times$ material confound. In our present studies, as well as in the Burke et al. (1992) and Heuer and Reisberg (1990) studies, the emotional characteristics of the stimuli were not manipulated independently of other characteristics of the stimuli. In other words, there may be other features of the hospital and garage slides during Phase 2 (e.g., distinctiveness or familiarity) that may be responsible for the memory effects. We are convinced that this confound is the most important issue in this area of research, and, unfortunately, we are not aware of any studies that completely address the problem.

There are a few studies, however, that are suggestive. Cahill and McGaugh (1995) used the same slide presentation for both the neutral and the emotional conditions (basically, the hospital story) and manipulated emotional arousal by changing the narratives. These authors found that memory was enhanced for the emotional arousal narrative condition, relative to the neutral narrative condition. Unfortunately, memory for central and background detail were not measured. Most important, however, it is possible that the subjects were differentially influenced by the narratives - for example, directing the subject's attention to different aspects of the slides or spending more time on one feature than on another fea- 
ture. Cahill, Prins, Weber, and McGaugh (1994), using the same methodology as that in Cahill and McGaugh (i.e., the hospital story with different narratives to induce emotional arousal), gave subjects propranolol (a $\beta$ adrenergic receptor antagonist that is known to block emotional arousal that results from the activation of the $\beta$-adrenergic stress hormone systems) before the slide presentation. Cahill et al. reported that propranolol (in contrast with a placebo condition) impaired memory for the emotionally arousing narration, relative to the neutral narration. Of course, this finding does not rule out the possibility that other changes in the narratives besides its emotional content may be producing the physiological effects. Cahill and McGaugh concluded that changes in emotional arousal are associated with changes in memory. In other words, it is still not possible to rule out other factors. In fact, Cahill and McGaugh suggest that these other factors may be an integral part of any emotional arousal manipulation.

\section{Theory}

How do we account for these effects? On the basis of our hypotheses, the flashbulb theory (Brown \& Kulik, 1977 ) is supported, and the cue utilization theory is not supported (Easterbrook, 1959). What is compelling about the flashbulb theory is the assumption that these memories contain detailed information surrounding the event as well as the event itself. Is it, therefore, reasonable to assume that our experiments are laboratory analogues of the flashbulb memory phenomenon? Unfortunately, there are properties of flashbulb memories that were not examined in our studies (e.g., permanence and vividness). Furthermore, requisites of flashbulb memories include consequentiality and surprise (Brown \& Kulik, 1977). In our studies (as well as in previous studies in this areasee Schmidt, 1991), the relative contribution of these variables has not been independently determined. In fact, the importance of these variables in determining flashbulb memories has largely been established on the basis of retrospective reports. Our data suggest that consequentiality may be important in establishing flashbulb memories. We do, however, question the construct of surprise.

In terms of the consequentiality criterion, our rating scale data did indicate that the subjects perceived the hospital story to be emotional and that they experienced an emotional reaction to the story. Furthermore, emotional ratings for the individual slides indicate that the subjects were strongly affected by Slides 5-8 in the hospital condition. According to Brown and Kulik (1977), stimuli that produce emotional reactions are consequentialthat is, they have evolutionary or personal significance. Unsolicited comments from the subjects during the procedure ("oh my God," "that's disgusting," "that's sick, really sick") support the rating scale data. However, this argument is weakened because, in contrast to Burke et al. (1992) and Heuer and Reisberg (1990), we failed to find any evidence that would support the existence of an orienting response. Note, however, that their orienting re- sponse is atypical. A typical orienting response is indicative of increased attention to a novel stimulus and is accompanied by heart rate deceleration and feelings of pleasantness, whereas a defensive response is indicative of blocking of an external stimulus and is accompanied by heart rate acceleration and feelings of unpleasantness (Schmidt, 1991). Burke et al. and Heuer and Reisberg (1990) found heart rate deceleration, but it is doubtful that it was accompanied by feelings of pleasantness. Schmidt (1991), in interpreting the Heuer and Reisberg (1990) data, suggested that, given the complicated nature of the stimuli (i.e., the content of the slides), components of both responses may occur-for example, increased attention and feelings of unpleasantness. Schmidt also suggested that memory enhancement for central detail and memory suppression for background detail would only occur when a pure defensive reaction is elicited. Of course, Burke et al. reported enhancement for central detail and suppression for background detail with heart rate deceleration. Overall, there appear to be interpretative problems with the Heuer and Reisberg (1990) and Burke et al. heart rate data, even if it is assumed that their heart rate data are reliable. Therefore, given the present set of circumstances, it may be best to rely on the rating scale data. These data (in the Heuer \& Reisberg, 1990, and Burke et al. studies, and in our studies) indicate that the subjects were emotionally aroused by the hospital story.

In terms of the surprise criterion, Brown and Kulik (1977) focused on the novelty and unexpectedness of the emotional event. In our research, the emotional events may have been somewhat novel; we doubt that these events were totally unexpected. Although no instructions were given to the subjects indicating the emotional nature of the slides, the subjects could have inferred from Phase 1 (in the emotional story, Slide 4 contains a building labeled Victory Memorial Hospital, and the accompanying narrative indicates that the father is a surgeon) that a traumatic event was forthcoming. These cues could activate a story schema indicating that one should prepare for the possible viewing of a traumatic event. In this scenario, it would not be necessary for the schemata to contain details about the emotional event per se, other than to indicate that medical settings are associated with negative events. The construct of preparedness would also contain arousal. Given the ambiguous nature of the forthcoming aversive event, increments in arousal could elicit/produce scanning of the environment in order to gain more information about the event. Thus, the subjects would remember background as well as the central details of the traumatic event. This view of arousal is consistent with Revelle and D. A. Loftus's (1992) tick rate hypothesis, according to which increases in arousal are assumed to lead to increases in environmental sampling, and Kahneman's (1973) view that increases in arousal lead to increases in attentional capacity.

Our view is also consistent with some of the results in the anxiety literature. Although research has indicated that highly anxious individuals may have an attentional 
bias (Broadbent \& Broadbent, 1988; Mogg, Mathews, Eysenck, \& May, 1991) or may selectively process threat cues (see, e.g., Martin, Williams, \& Clark, 1991; Mathews, Richards, \& Eysenck, 1989; Mogg et al., 1991), Shapiro and $\operatorname{Lim}(1989)$ reported that anxious subjects perceive and respond to neutral peripheral cues more readily than do nonanxious subjects. Beck and Emery (1985) refer to this as hypervigilance. In essence, when individuals are anxious, they scan the environment for threat cues. Because they are actively scanning, these individuals will perceive, attend to, and encode more peripheral cues than will nonanxious individuals.

Finally, it is important to note that the theories of flashbulb memory and hypervigilance rely on an evolutionary perspective (Brown \& Kulik, 1977; Shapiro \& Lim, 1989). It is assumed that any mechanism that improves memory for threatening situations or events would have survival value, both for the individual and for the species. A hypervigilance mechanism would have the added advantage of increasing the probability of perceiving threat cues in similar threatening situations in the future, thereby optimizing the opportunity for escape or defense.

Where does this view fit within the broader context? Christianson (1992a, 1992b) proposed that the initial stages of the processing of emotional information involve automatic or preattentive processing, whereas the later stages involve controlled or conceptual processing. The automatic processes are assumed to be parallel, nonconscious, context independent, and fast, whereas the controlled processes are assumed to be serial, to require intention and effort, and to depend on limited processing resources. On the basis of this two-stage model, Christianson (1992a) predicts that memory for central detail will be enhanced and memory for background detail diminished. This prediction is largely based on the assumption that, during controlled processing, individuals will focus their efforts on the emotional stimuli. Our data suggest that the processing of emotional stimuli is largely controlled by the initial stages of processing. In our experiments, the subjects, after viewing the slides, were given the emotionality rating scales, followed by a $10-15 \mathrm{~min}$ filler task and then the memory test. Although controlled processing cannot be ruled out, it is unlikely that much poststimulus elaboration occurred during the time between slide presentation and memory testing. The view that the processing of emotional stimuli is largely an automatic process is consistent with Conway et al.'s (1994) model of flashbulb memory, in which rehearsal plays a secondary role, and with the literature that supports the notion that arousal at input improves memory (Craik \& Blankstein, 1975; Eysenck, 1976; Gold, 1987).

\section{Retrograde Amnesia}

Finally, we would like to comment on the finding that, during Phase 1, memory was superior for the garage story, relative to the hospital story. This effect occurred for background detail in the recognition experiments. Although not evident in the cued recall experiment, it is worth noting, because these memory differences occurred prior to the advent of the emotional stimuli.

How can we account for these effects? One possibility is that, inasmuch as Slide 4 differed for the two story conditions, the content of these slides may be responsible for the effect. However, when analyses were conducted with Slide 4 placed in Phase 2 or when Slide 4 was omitted, the memory advantage for the garage story in Phase 1 was still evident. Another possibility is retrograde amnesia - that is, exposure to the emotional stimuli during Phase 2 led to memory performance losses during Phase 1 . There are studies that report similar findings, using analogous methodologies. Tulving (1969) and Saufley and Winograd (1970) reported that inserting famous names in otherwise homogeneous word lists led to retrograde amnesia. Detterman and Ellis (1972) reported similar effects when a photographed nude was inserted into a list of line drawings. Finally, and very similar to our procedure, E. F. Loftus and Burns (1982) found retrograde amnesia when a violent scene was inserted into a slide sequence.

\section{Conclusion}

The results of the present experiments indicate that memory for central and background detail was enhanced by emotional arousal but not by physiological arousal. These findings support the notions that the source of arousal is an important determinant of an event's memorability and that emotional arousal increases the scope of memory.

\section{REFERENCES}

Beck, A. T., \& EMery, G. (1985). Anxiety disorders and phobias: A cognitive perspective. New York: Basic Books.

BoHanNon, J. N. ( 1988). Flashbulb memories for the space shuttle disaster. A tale of two theories. Cognition, 29, 179-196.

BROADBENT, D. E. (1971). Decision and stress. London: Academic Press. BroadBent, D. E., \& BroadBent, M. (1988). Anxiety and attentional bias: State and trait. Cognition \& Emotion, 2, 165-183.

Brown, R., \& KulıK, J. (1977). Flashbulb memories. Cognition, 5, 73-99.

Burke, A., Heuer, F., \& ReisBerg, D. (1992). Remembering emotional events. Memory \& Cognition, 20, 277-290.

Cahill, L., \& McGaugh, J. L. (1995). A novel demonstration of enhanced memory associated with emotional arousal. Consciousness \& Cognition, 4, 410-421.

Cahill, L., Prins, B., Weber, M., \& McGaugh, J. L. (1994). $\beta$-Adrenergic activation and memory for emotional events. Nature, 371, 702704.

Christianson, S. $\AA$. (1989). Flashbulb memories: Special, but not so special. Memory \& Cognition, 17, 435-443.

Christianson, S.-Å. (1992a). Emotional stress and eyewitness memory: A critical review. Psychological Bulletin, 112, 284-309.

Christianson, S.-A. (1992b). The handbook of emotion and memory: Research and theory. Hillsdale, NJ: Erlbaum.

Christianson, S.-Å., \& Loftus, E. F. (1987). Memory for traumatic events. Applied Cognitive Psychology, 1, 225-239.

Christianson, S.-Å., \& Muörndal, T. (1985). Adrenaline, emotional arousal and memory. Scandinavian Journal of Psychology, 26, 237248.

Christianson, S.- $\AA .$, Nilsson, L. G., Muörndal, T., Perris, C., \& TJELLDEN, G. (1986). Psychological versus physiological determinants of emotional arousal and its relationship to laboratory induced amnesia. Scandinavian Journal of Psychology, 27, 300-310. 
CoHen, N. J., MCCloskey, M., \& WiBle, C. G. (1988). There is still no case for a flashbulb-memory mechanism: Reply to Schmidt and Bohannon. Journal of Experimental Psychology: General, 117, 336-338.

Cohen, N. J., McCloskey, M., \& Wible, C. G. (1990). Flashbulb memories and underlying cognitive mechanisms: Reply to Pillemer. Journal of Experimental Psychology: General, 119, 97-100.

Conway, M. A. (1995). Flashbulb memories. Hillsdale, NJ: Erlbaum.

Conway, M. A., Anderson, S. J., Larsen, S. F., Donnelly, C. M., MCDaniel, M. A., McClelland, A. G. R., Rawles, R. E., \& Logie, R. H. (1994). The formation of flashbulb memories. Memory \& Cognition, 22, 326-343.

Craik, F. I. M., \& Blankstein, K. R. (1975). Psychophysiology and human memory. In P. H. Venables \& M. J. Christie (Eds.), Research in psychophysiology (pp. 388-417). London: Wiley.

Cutler, B. L., Penrod, S., \& Martins, T. K. (1987). The reliability of eyewitness identification: The role of system and estimator variables. Law \& Human Behavior, 11, 233-258.

Detterman, D. K., \& Ellis, N. R. (1972). Determinants of induced amnesia in short-term memory. Journal of Experimental Psychology, 95, 308-316

DuFFY, E. (1962). Activation and behavior. New York: Wiley.

EASTERBROOK, J. A. (1959). The effect of emotion on cue utilization and the organization of behavior. Psychological Review, 66, 183-201.

EYsENCK, M. W. (1976). Arousal, learning, and memory. Psychological Bulletin, 83, 389-404

EYSENCK, M. W. (1977). Human memory: Theory, research and individual differences. New York: Pergamon.

GoLD, P. (1987). Sweet memories. American Scientist, 75, 151-155.

HEART RATE MONITOR BUYER's GUIDE (1992, November). Creative Health Products, pp. 1-4.

Heuer, F. \& Reisberg, D. (1990). Vivid memories of emotional events: The accuracy of remembered minutiae. Memory \& Cognition, 18, 496-506.

HeUER, F., \& REISBERG, D. (1992). Emotion, arousal, and memory for detail. In S. $\AA$. Christianson (Ed.), The handbook of emotion and memory: Research and theory (pp. 151-180). Hillsdale, NJ: Erlbaum.

HumphreYs, M. S., \& Revel.LE, W. (1984). Personality, motivation and performance: A theory of the relationship between individual differences and information processing. Psychological Review, 91, 153-182.

KaHneman, D. (1973). Attention and effort. Englewood Cliffs, NJ: Prentice-Hall.

KRAMER, T. H., Buckhout, R., \& Eugenio, P. (1990). Weapon focus, arousal, and eyewitness memory. Law \& Human Behavior, 14, 167-185.

LACEY, J. I. (1967). Somatic response patterning and stress: Some revisions for activation theory. In M. M. Appley \& R. Trumbull (Eds.), Psychological stress (pp. 14-36). New York: Appleton-CenturyCrofts.

LÉGER, L., \& Thivierge, M. (1988). Heart rate monitors: Validity, stability, and functionality. Physician \& Sports Medicine, 16, 143-151.

LIVINGSTON, R. (1967). Brain circuitry relating to complex behavior. In G. C. Quarton, T. Melnechuck, and F. O. Schmitt (Eds.), The neurosciences: A study program (pp. 499-514). New York: Rockefeller University Press.

LofTUs, E. F. (1979). Eyewitness testimony. Cambridge, MA: Harvard University Press.

Loftus, E. F., \& BuRNs, T. E. (1982). Mental shock can produce retrograde amnesia. Memory \& Cognition, 10, 318-323.

LofTus, E. F., LofTus, G. R., \& Messo, J. (1987). Some facts about "weapon focus." Law \& Human Behavior, 11, 55-62.

LofTus, G. R., \& Masson, M. E. J. (1994). Using confidence intervals in within-subject designs. Psychonomic Bulletin \& Review, 1, 476490.

MaASS, A., \& KoHNKen, G. (1989). Eyewitness identification: Simulating the "weapon effect." Law \& Human Behavior, 13, 397-408.

MANDLER, G. (1992). Memory, arousal, and mood: A theoretical inte- gration. In S.- $\AA$. Christianson (Ed.), The handbook of emotion and memory: Research and theory (pp. 93-1 10). Hillsdale, NJ: Erlbaum.

Martin, M., Williams, R. M., \& Cl.ark, D. M. (1991). Does anxiety lead to selective processing of threat-related information? Behaviour Research \& Therapy, 29, 147-160.

MATHEWs, A., RichaRDS, A., \& EYSENCK, M. (1989). Journal of Abnormal Psychology, 98, 31-34.

MCCloskey, M., Wible, C. G., \& Cohen, N. J. (1988). Is there a special flashbulb-memory mechanism? Journal of Experimental Psychology: General, 117, 171-181.

Mogg, K., Mathews, A., Eysenck, M., \& MaY, J. (1991). Biased cognitive operations in anxiety: Artifact, processing priorities or attentional search? Behaviour Research \& Therapy, 29, 459-467.

NeISs, R. (1988a). Reconceptualizing arousal: Psychological states in motor performance. Psychological Bulletin, 103, 345-366.

NeIss, R. (1988b). Reconceptualizing relaxation treatments: Psychobiological states in sports. Clinical Psychology Review, 8, 139-159.

Pillemer, D. B. (1990). Clarifying the flashbulb memory concept: Comment on McCloskey, Wible, and Cohen (1988). Journal of Experimental Psychology: General, 119, 92-96.

REvElLE, W., \& LOFTUS, D. A. (1992). The implications of arousal effects for the study of affect and memory. In S.-A. Christianson (Ed.), The handbook of emotion and memory: Research and theory (pp. 113149). Hillsdale, NJ: Erlbaum.

SAUFLEY, W. H., JR., \& WinOGRAD, E. (1970). Retrograde amnesia and priority instructions in free recall. Journal of Experimental Psychology, 85, 150-152.

SChaChTER, S., \& Singer, J. E. (1962). Cognitive, social and physiological determinants of emotional state. Psychological Review, 69. 379-399.

SCHMIDT, S. R. (1991). Can we have a distinctive theory of memory? Memory \& Cognition, 19, 523-542.

Schmidt, S. R., \& Bohannon, J. N., III (1988). In defense of the flashbulb-memory hypothesis: A comment on McCloskey, Wible, \& Cohen (1988). Journal of Experimental Psychology: General, 117, 332-335.

Shapiro, K. L., \& Lim, A. (1989). The impact of anxiety on visual attention to central and peripheral events. Behaviour Research Therapy, 27, 345-351.

Sinclair, R. C., Hoffman, C., Mark, M. M., Martin, L. L., \& PickERING, T. L. (1994). Construct accessibility and the misattribution of arousal: Schachter and Singer revisited. Psychological Science, 5 , $15-19$.

Steblay, N. M. (1992). A meta-analytic review of the weapon focus effect. Law \& Human Behavior, 16, 413-424.

TrouvÉ, R. J., \& LibKuman, T. M. (1992). Eyewitness performance of personality types as a function of induced arousal. American Journal of Psychology, 105, 417-433.

Tulving, E. (1969). Retrograde amnesia in free recall. Science, 164, 88-90.

WEAVER, C. A., III (1993). Do you need a "flash" to form a flashbulb memory? Journal of Experimental Psychology: General, 122, 39-46.

WICKENS, C. D. (1984). Processing resources in attention. In R. Parasuraman \& D. R. Davies (Eds.), Varieties of attention (pp. 66-102). New York: Academic Press.

Wilhite, S. C., \& PAYNE, D. E. (1992). Learning and memory. Boston: Allyn and Bacon.

YERKES, R. M., \& DODSON, J. D. (1908). The relation of strength of stimulus to rapidity of habit formation. Journal of Comparative Neurology \& Psychology, 18, 459-482.

\section{NOTE}

1. We would like to thank Daniel Reisberg for permission to use his slides. 
APPENDIX

\section{EXPERIMENT 1}

\section{Heart Rate Measures}

Baseline I (Before Physiological Arousal)

\begin{tabular}{llcc}
$\begin{array}{l}\text { Physiological } \\
\text { Arousal }\end{array}$ & Story & $M$ & $S E$ \\
\hline No exercise & Garage & 77.70 & 2.49 \\
& Hospital & 79.30 & 2.87 \\
Exercise & Garage & 76.45 & 2.93 \\
& Hospital & 76.00 & 3.50 \\
\hline
\end{tabular}

Baseline 2 (After Physiological Arousal)

\begin{tabular}{llrl}
$\begin{array}{l}\text { Physiological } \\
\text { Arousal }\end{array}$ & Story & $M$ & $S E$ \\
\hline No exercise & Garage & 79.65 & 2.31 \\
& Hospital & 81.40 & 3.40 \\
Exercise & Garage & 135.30 & 4.28 \\
& Hospital & 143.35 & 4.49 \\
\hline
\end{tabular}

During Slide Presentation (4 sec After Slide Onset)

\begin{tabular}{|c|c|c|c|c|c|c|c|}
\hline \multirow{3}{*}{$\begin{array}{c}\text { Physiological } \\
\text { Arousal }\end{array}$} & \multirow[b]{3}{*}{ Story } & \multicolumn{6}{|c|}{ Phase } \\
\hline & & \multicolumn{2}{|l|}{1} & \multicolumn{2}{|c|}{2} & \multicolumn{2}{|c|}{3} \\
\hline & & $M$ & $S E$ & $M$ & $\overline{S E}$ & $M$ & $S E$ \\
\hline \multirow[t]{2}{*}{ No exercise } & Garage & 80.95 & 2.11 & 77.85 & 2.27 & 77.80 & 2.32 \\
\hline & Hospital & 80.15 & 3.20 & 77.30 & 3.14 & 77.30 & 3.22 \\
\hline \multirow[t]{2}{*}{ Exercise } & Garage & 102.70 & 5.27 & 87.45 & 4.63 & 82.25 & 4.20 \\
\hline & Hospital & 108.10 & 5.95 & 90.65 & 5.52 & 83.95 & 5.11 \\
\hline
\end{tabular}

During Slide Presentation (Lowest Heart Rate for Each Slide)

\begin{tabular}{|c|c|c|c|c|c|c|c|c|c|c|c|c|}
\hline \multirow[b]{2}{*}{ Story } & \multicolumn{12}{|c|}{ Slide } \\
\hline & 1 & 2 & 3 & 4 & 5 & 6 & 7 & 8 & 9 & 10 & 11 & 12 \\
\hline \multicolumn{13}{|l|}{$\overline{\text { Garage }}$} \\
\hline$M$ & 83.92 & 80.50 & 80.14 & 77.43 & 77.86 & 76.79 & 76.93 & 77.57 & 77.43 & 76.64 & 76.71 & 77.57 \\
\hline$S E$ & 2.99 & 2.34 & 2.49 & 2.91 & 2.89 & 3.13 & 3.09 & 2.92 & 2.87 & 2.81 & 2.87 & 3.05 \\
\hline \multicolumn{13}{|l|}{ Hospital } \\
\hline$\dot{M}$ & 83.94 & 82.24 & 80.06 & 78.94 & 79.82 & 79.06 & 78.24 & 77.71 & 77.82 & 78.59 & 79.00 & 79.59 \\
\hline$S E$ & 3.64 & 3.57 & 3.29 & 3.23 & 3.21 & 3.42 & 3.40 & 3.40 & 3.35 & 3.44 & 3.56 & 3.48 \\
\hline
\end{tabular}

\section{Rating Scale Measures}

Emotionality of Slide Presentation

\begin{tabular}{llcc}
\hline $\begin{array}{l}\text { Physiological } \\
\text { Arousal }\end{array}$ & Story & $M$ & $S E$ \\
\hline No exercise & Garage & 2.75 & 0.46 \\
& Hospital & 5.70 & 0.45 \\
Exercise & Garage & 2.65 & 0.33 \\
& Hospital & 5.55 & 0.38 \\
\hline
\end{tabular}

Reaction to Slide Presentation

\begin{tabular}{llcr}
\hline $\begin{array}{l}\text { Physiological } \\
\text { Arousal }\end{array}$ & Story & $M$ & $S E$ \\
\hline No exercise & Garage & 2.45 & 0.39 \\
& Hospital & 5.25 & 0.39 \\
Exercise & Garage & 2.30 & 0.31 \\
& Hospital & 4.75 & 0.42 \\
\hline
\end{tabular}




\section{APPENDIX (Continued)}

\section{Memory Measures}

Gist

\begin{tabular}{|c|c|c|c|c|c|c|c|}
\hline \multirow{3}{*}{$\begin{array}{c}\text { Physiological } \\
\text { Arousal }\end{array}$} & \multirow[b]{3}{*}{ Story } & \multicolumn{6}{|c|}{ Phase } \\
\hline & & \multicolumn{2}{|c|}{1} & \multicolumn{2}{|c|}{2} & \multicolumn{2}{|c|}{3} \\
\hline & & $M$ & $S E$ & $M$ & $S E$ & $M$ & $S E$ \\
\hline \multirow[t]{2}{*}{ No exercise } & Garage & 79.00 & 3.76 & 82.00 & 3.29 & 93.00 & 2.52 \\
\hline & Hospital & 74.50 & 2.46 & 79.50 & 3.12 & 86.50 & 3.02 \\
\hline \multirow[t]{2}{*}{ Exercise } & Garage & 75.00 & 4.14 & 83.00 & 4.05 & 88.00 & 3.53 \\
\hline & Hospital & 72.00 & 4.02 & 82.50 & 3.47 & 89.00 & 2.98 \\
\hline
\end{tabular}

Central Detail

\begin{tabular}{|c|c|c|c|c|c|c|c|}
\hline \multirow{3}{*}{$\begin{array}{c}\text { Physiological } \\
\text { Arousal }\end{array}$} & \multirow[b]{3}{*}{ Story } & \multicolumn{6}{|c|}{ Phase } \\
\hline & & \multicolumn{2}{|c|}{1} & \multicolumn{2}{|c|}{2} & \multicolumn{2}{|c|}{3} \\
\hline & & $M$ & $S E$ & $M$ & $S E$ & $M$ & $S E$ \\
\hline \multirow[t]{2}{*}{ No exercise } & Garage & 42.00 & 3.52 & 54.00 & 3.36 & 50.50 & 4.01 \\
\hline & Hospital & 49.50 & 4.14 & 58.89 & 3.13 & 47.50 & 3.31 \\
\hline \multirow[t]{2}{*}{ Exercise } & Garage & 42.00 & 4.21 & 54.50 & 3.59 & 49.50 & 2.46 \\
\hline & Hospital & 47.00 & 3.85 & 62.78 & 2.32 & 44.50 & 4.38 \\
\hline
\end{tabular}

Background Detail

\begin{tabular}{|c|c|c|c|c|c|c|c|}
\hline \multirow{3}{*}{$\begin{array}{c}\text { Physiological } \\
\text { Arousal }\end{array}$} & \multirow[b]{3}{*}{ Story } & \multicolumn{6}{|c|}{ Phase } \\
\hline & & \multicolumn{2}{|c|}{1} & \multicolumn{2}{|c|}{2} & \multicolumn{2}{|c|}{3} \\
\hline & & $M$ & $S E$ & $M$ & $S E$ & $M$ & $S E$ \\
\hline \multirow[t]{2}{*}{ No exercise } & Garage & 37.00 & 3.00 & 28.50 & 2.84 & 36.00 & 2.94 \\
\hline & Hospital & 27.00 & 3.49 & 48.12 & 3.66 & 38.50 & 3.86 \\
\hline \multirow[t]{2}{*}{ Exercise } & Garage & 37.00 & 3.41 & 34.50 & 2.76 & 37.50 & 3.62 \\
\hline & Hospital & 26.00 & 2.34 & 50.00 & 3.39 & 42.00 & 4.39 \\
\hline
\end{tabular}


APPENDIX (Continued)

\section{EXPERIMENT 2}

\section{Heart Rate Measures}

Baseline 1 (Before Physiological Arousal)

\begin{tabular}{llcc}
\hline $\begin{array}{l}\text { Physiological } \\
\text { Arousal }\end{array}$ & Story & $M$ & $S E$ \\
\hline No exercise & Garage & 79.55 & 2.63 \\
& Hospital & 83.75 & 2.03 \\
Exercise & Garage & 77.47 & 3.36 \\
& Hospital & 85.70 & 3.34 \\
\hline
\end{tabular}

Baseline 2 (After Physiological Arousal)

\begin{tabular}{llrc}
\hline $\begin{array}{l}\text { Physiological } \\
\text { Arousal }\end{array}$ & Story & $M$ & $S E$ \\
\hline No exercise & Garage & 77.00 & 2.70 \\
& Hospital & 80.30 & 2.27 \\
Exercise & Garage & 141.95 & 4.03 \\
& Hospital & 142.45 & 2.84 \\
\hline
\end{tabular}

During Slide Presentation (4 sec After Slide Onset)

\begin{tabular}{|c|c|c|c|c|c|c|c|}
\hline \multirow{3}{*}{$\begin{array}{c}\text { Physiological } \\
\text { Arousal }\end{array}$} & \multirow[b]{3}{*}{ Story } & \multicolumn{6}{|c|}{ Phase } \\
\hline & & \multicolumn{2}{|c|}{1} & \multicolumn{2}{|c|}{2} & \multicolumn{2}{|c|}{3} \\
\hline & & $M$ & $S E$ & $M$ & $S E$ & $M$ & $S E$ \\
\hline \multirow[t]{2}{*}{ No exercise } & Garage & 78.95 & 2.54 & 75.95 & 2.27 & 75.60 & 2.23 \\
\hline & Hospital & 80.05 & 2.49 & 77.15 & 2.42 & 76.90 & 2.32 \\
\hline \multirow[t]{2}{*}{ Exercise } & Garage & 107.74 & 3.74 & 88.42 & 4.36 & 79.37 & 4.31 \\
\hline & Hospital & 109.85 & 4.23 & 89.30 & 4.71 & 82.90 & 4.41 \\
\hline
\end{tabular}

During Slide Presentation (Lowest Heart Rate for Each Slide)

\begin{tabular}{crrrrrrrrrrrrr}
\hline & \multicolumn{10}{c}{ Slide } \\
\cline { 2 - 14 } Story & 1 & 2 & 3 & 4 & 5 & 6 & 7 & 8 & 9 & 10 & 11 & 12 \\
\hline Garage & & & & & & & & & & & & \\
$M$ & 82.20 & 78.30 & 76.60 & 76.00 & 75.30 & 75.85 & 75.50 & 74.60 & 75.50 & 75.25 & 74.25 & 74.65 \\
$S E$ & 3.09 & 2.49 & 2.18 & 2.19 & 2.14 & 2.25 & 2.21 & 2.17 & 2.47 & 2.38 & 2.31 & 2.19 \\
Hospital & & & & & & & & & & & & \\
$M$ & 82.95 & 79.32 & 77.95 & 77.26 & 77.63 & 77.00 & 76.00 & 75.32 & 75.47 & 76.42 & 76.68 & 76.53 \\
$S E$ & 2.90 & 2.83 & 2.46 & 2.58 & 2.56 & 2.61 & 2.66 & 2.50 & 2.52 & 2.50 & 2.48 & 2.48 \\
\hline
\end{tabular}

\section{Rating Scale Measures}

Emotionality of Slide Presentation

\begin{tabular}{llcc}
\hline $\begin{array}{l}\text { Physiological } \\
\text { Arousal }\end{array}$ & Story & $M$ & $S E$ \\
\hline No exercise & Garage & 3.00 & 0.44 \\
& Hospital & 4.65 & 0.44 \\
Exercise & Garage & 2.37 & 0.39 \\
& Hospital & 6.30 & 0.32 \\
\hline
\end{tabular}

Reaction to Slide Presentation

\begin{tabular}{llcc}
\hline $\begin{array}{llll}\text { Physiological } \\
\text { Arousal }\end{array}$ & Story & $M$ & $S E$ \\
\cline { 1 - 2 } No exercise & Garage & 2.55 & 0.42 \\
& Hospital & 4.20 & 0.42 \\
Exercise & Garage & 2.26 & 0.31 \\
& Hospital & 6.00 & 0.24 \\
\hline
\end{tabular}


APPENDIX (Continued)

\section{Memory Measures}

\begin{tabular}{|c|c|c|c|c|c|c|c|}
\hline \multirow{3}{*}{$\begin{array}{c}\text { Physiological } \\
\text { Arousal }\end{array}$} & \multirow[b]{3}{*}{ Story } & \multicolumn{6}{|c|}{ Phase } \\
\hline & & \multicolumn{2}{|c|}{1} & \multicolumn{2}{|c|}{2} & \multicolumn{2}{|c|}{3} \\
\hline & & $M$ & $S E$ & $M$ & $S E$ & $M$ & $S E$ \\
\hline \multirow[t]{2}{*}{ No exercise } & Garage & 65.71 & 3.50 & 73.33 & 3.17 & 85.56 & 2.30 \\
\hline & Hospital & 63.75 & 4.25 & 60.00 & 4.31 & 70.00 & 4.28 \\
\hline \multirow[t]{2}{*}{ Exercise } & Garage & 66.16 & 4.53 & 75.44 & 3.66 & 85.38 & 3.18 \\
\hline & Hospital & 65.00 & 4.22 & 64.38 & 3.66 & 74.44 & 3.43 \\
\hline
\end{tabular}

Central Detail

\begin{tabular}{|c|c|c|c|c|c|c|c|}
\hline \multirow{3}{*}{$\begin{array}{c}\text { Physiological } \\
\text { Arousal }\end{array}$} & \multirow[b]{3}{*}{ Story } & \multicolumn{6}{|c|}{ Phase } \\
\hline & & \multicolumn{2}{|c|}{1} & \multicolumn{2}{|c|}{2} & \multicolumn{2}{|c|}{3} \\
\hline & & $M$ & $S E$ & $M$ & $S E$ & $M$ & $S E$ \\
\hline \multirow[t]{2}{*}{ No exercise } & Garage & 48.33 & 3.95 & 37.27 & 2.79 & 45.00 & 4.07 \\
\hline & Hospital & 45.42 & 2.67 & 50.50 & 3.20 & 43.89 & 3.47 \\
\hline \multirow[t]{2}{*}{ Exercise } & Garage & 51.75 & 3.16 & 41.15 & 3.14 & 41.52 & 3.38 \\
\hline & Hospital & 47.92 & 4.31 & 53.50 & 2.74 & 40.00 & 3.46 \\
\hline
\end{tabular}

Background Detail

\begin{tabular}{|c|c|c|c|c|c|c|c|}
\hline \multirow{3}{*}{$\begin{array}{c}\text { Physiological } \\
\text { Arousal }\end{array}$} & \multirow[b]{3}{*}{ Story } & \multicolumn{6}{|c|}{ Phase } \\
\hline & & \multicolumn{2}{|c|}{1} & \multicolumn{2}{|c|}{2} & \multicolumn{2}{|c|}{3} \\
\hline & & $M$ & $S E$ & $M$ & $S E$ & $M$ & $S E$ \\
\hline \multirow[t]{2}{*}{ No exercise } & Garage & 22.86 & 4.07 & 24.00 & 3.03 & 27.22 & 3.82 \\
\hline & Hospital & 19.38 & 3.07 & 30.71 & 2.80 & 21.11 & 3.21 \\
\hline \multirow[t]{2}{*}{ Exercise } & Garage & 24.81 & 4.74 & 20.53 & 1.94 & 31.58 & 4.01 \\
\hline & Hospital & 31.25 & 3.90 & 31.43 & 2.66 & 23.89 & 2.59 \\
\hline
\end{tabular}


APPENDIX (Continued)

\section{EXPERIMENT 3}

\section{Heart Rate Measures}

Baseline I (Before Physiological Arousal)

\begin{tabular}{llll}
\hline Physiological & & & \\
Arousal & Story & $M$ & $S E$ \\
\hline No exercise & Garage & 81.62 & 3.99 \\
& Hospital & 82.00 & 2.44 \\
Low exercise & Garage & 82.38 & 3.12 \\
& Hospital & 83.30 & 2.27 \\
Exercise & Garage & 82.52 & 3.41 \\
& Hospital & 81.67 & 2.45 \\
\hline
\end{tabular}

Baseline 2 (After Physiological Arousal)

\begin{tabular}{llcc}
\hline Physiological & & & \\
Arousal & Story & $M$ & $S E$ \\
\hline No exercise & Garage & 76.90 & 3.70 \\
& Hospital & 80.77 & 2.55 \\
Low exercise & Garage & 82.19 & 3.70 \\
& Hospital & 81.05 & 2.34 \\
Exercise & Garage & 86.86 & 4.08 \\
& Hospital & 86.05 & 3.86 \\
\hline
\end{tabular}

During Slide Presentation (Summed and Averaged for Each Slide)

\begin{tabular}{|c|c|c|c|c|c|c|c|}
\hline \multirow{3}{*}{$\begin{array}{c}\text { Physiological } \\
\text { Arousal }\end{array}$} & \multirow[b]{3}{*}{ Story } & \multicolumn{6}{|c|}{ Phase } \\
\hline & & \multicolumn{2}{|c|}{1} & \multicolumn{2}{|c|}{2} & \multicolumn{2}{|c|}{3} \\
\hline & & $M$ & $S E$ & $M$ & $S E$ & $M$ & $S E$ \\
\hline \multirow[t]{2}{*}{ No exercise } & Garage & 81.52 & 3.68 & 80.81 & 3.81 & 81.05 & 3.86 \\
\hline & Hos & 8 & 2.62 & 84 & 2.61 & 85.64 & 2.98 \\
\hline \multirow{2}{*}{ Low exercise } & Garage & 96.95 & 3.43 & 96.10 & 3.49 & 94.71 & 3.61 \\
\hline & Hospital & 97.90 & 2.67 & 96.80 & 2.72 & 95.90 & 2.68 \\
\hline \multirow[t]{2}{*}{ Exercise } & Garage & 120.38 & 4.94 & 121.90 & 4.81 & 123.10 & 5.25 \\
\hline & Hospital & 120.48 & 4.01 & 119.57 & 4.33 & 119.38 & 4.62 \\
\hline
\end{tabular}

During Slide Presentation (2 sec After Slide Onset)

\begin{tabular}{|c|c|c|c|c|c|c|c|c|c|c|c|c|}
\hline \multirow[b]{2}{*}{ Story } & \multicolumn{12}{|c|}{ Slide } \\
\hline & 1 & 2 & 3 & 4 & 5 & 6 & 7 & 8 & 9 & 10 & 11 & 12 \\
\hline \multicolumn{13}{|l|}{ Garage } \\
\hline$M$ & 85.05 & 81.33 & 79.86 & 79.43 & 80.81 & 80.67 & 82.24 & 80.29 & 80.95 & 80.19 & 81.05 & 81.48 \\
\hline $\mathrm{S} E$ & 4.02 & 3.66 & 3.58 & 3.70 & 3.78 & 3.99 & 4.07 & 3.89 & 3.92 & 3.68 & 3.94 & 4.0 \\
\hline \multicolumn{13}{|l|}{ Hospital } \\
\hline$M$ & 87.90 & 85.68 & 84.59 & 84.00 & 84.46 & 84.41 & 84.41 & 83.73 & 85.04 & 85.27 & 85.59 & 86.23 \\
\hline$S E$ & 2.78 & 2.59 & 2.59 & 2.71 & 2.64 & 2.37 & 2.60 & 2.75 & 2.74 & 2.94 & 3.08 & 3.39 \\
\hline
\end{tabular}


APPENDIX (Continued)

\section{Rating Scale Measures}

Emotionality of Slide Presentation

\begin{tabular}{llcc}
\hline $\begin{array}{llc}\text { Physiological } \\
\text { Arousal }\end{array}$ & Story & $M$ & $S E$ \\
\hline No exercise & Garage & 2.80 & 0.42 \\
& Hospital & 5.45 & 0.44 \\
Low exercise & Garage & 2.38 & 0.38 \\
& Hospital & 6.00 & 0.38 \\
Moderate exercise & Garage & 3.33 & 0.48 \\
& Hospital & 5.05 & 0.47 \\
\hline
\end{tabular}

Reaction to Slide Presentation

\begin{tabular}{llcc}
\hline $\begin{array}{llc}\text { Physiological } \\
\text { Arousal }\end{array}$ & Story & $M$ & $S E$ \\
\hline No exercise & Garage & 2.57 & 0.39 \\
& Hospital & 4.41 & 0.43 \\
Low exercise & Garage & 2.67 & 0.41 \\
& Hospital & 5.05 & 0.44 \\
Moderate exercise & Garage & 3.14 & 0.50 \\
& Hospital & 4.38 & 0.47 \\
\hline
\end{tabular}

\section{Memory Measures}

Gist

\begin{tabular}{|c|c|c|c|c|c|c|c|}
\hline \multirow{3}{*}{$\begin{array}{c}\text { Physiological } \\
\text { Arousal }\end{array}$} & \multirow[b]{3}{*}{ Story } & \multicolumn{6}{|c|}{ Phase } \\
\hline & & \multicolumn{2}{|c|}{1} & \multicolumn{2}{|c|}{2} & \multicolumn{2}{|c|}{3} \\
\hline & & $\bar{M}$ & $S E$ & $M$ & $S E$ & $M$ & $S E$ \\
\hline \multirow[t]{2}{*}{ No exercise } & Garage & 76.19 & 4.45 & 77.62 & 4.14 & 86.19 & 4.39 \\
\hline & Hospital & 76.36 & 3.64 & 84.09 & 2.04 & 92.73 & 1.99 \\
\hline \multirow[t]{2}{*}{ Low exercise } & Garage & 72.38 & 3.65 & 76.19 & 4.05 & 87.14 & 3.46 \\
\hline & Hospital & 62.00 & 3.53 & 73.00 & 4.05 & 85.50 & 3.20 \\
\hline \multirow[t]{2}{*}{ Moderate exercise } & Garage & 72.38 & 3.16 & 69.52 & 4.86 & 85.24 & 3.14 \\
\hline & Hospital & 60.48 & 4.55 & 69.04 & 3.90 & 79.52 & 3.62 \\
\hline
\end{tabular}

Central Detail

\begin{tabular}{|c|c|c|c|c|c|c|c|}
\hline \multirow{3}{*}{$\begin{array}{c}\text { Physiological } \\
\text { Arousal }\end{array}$} & \multirow[b]{3}{*}{ Story } & \multicolumn{6}{|c|}{ Phase } \\
\hline & & \multicolumn{2}{|c|}{1} & \multicolumn{2}{|c|}{2} & \multicolumn{2}{|c|}{3} \\
\hline & & $M$ & $S E$ & $M$ & $S E$ & $M$ & $S E$ \\
\hline \multirow[t]{2}{*}{ No exercise } & Garage & 42.38 & 3.23 & 50.00 & 2.58 & 43.81 & 4.28 \\
\hline & Hospital & 38.64 & 3.96 & 58.59 & 2.85 & 44.54 & 3.53 \\
\hline \multirow{2}{*}{ Low exercise } & Garage & 35.24 & 2.98 & 45.23 & 3.06 & 49.52 & 4.05 \\
\hline & Hospital & 43.00 & 4.18 & 53.89 & 3.05 & 32.00 & 3.60 \\
\hline \multirow[t]{2}{*}{ Moderate exercise } & Garage & 34.76 & 4.00 & 42.86 & 3.02 & 34.29 & 2.14 \\
\hline & Hospital & 39.52 & 3.55 & 53.44 & 2.72 & 31.90 & 4.34 \\
\hline
\end{tabular}

Background Detail

\begin{tabular}{|c|c|c|c|c|c|c|c|}
\hline \multirow{3}{*}{$\begin{array}{c}\text { Physiological } \\
\text { Arousal }\end{array}$} & \multirow[b]{3}{*}{ Story } & \multicolumn{6}{|c|}{ Phase } \\
\hline & & \multicolumn{2}{|c|}{1} & \multicolumn{2}{|c|}{2} & \multicolumn{2}{|c|}{3} \\
\hline & & $M$ & $S E$ & $M$ & $S E$ & $M$ & $S E$ \\
\hline \multirow[t]{2}{*}{ No exercise } & Garage & 33.81 & 3.48 & 28.57 & 2.70 & 43.33 & 3.68 \\
\hline & Hospital & 23.64 & 3.39 & 47.16 & 3.07 & 31.36 & \\
\hline \multirow[t]{2}{*}{ Low exercise } & Garage & 24.29 & 3.49 & 31.90 & 2.73 & 38.10 & 4.1 \\
\hline & Hospital & 20.00 & 2.90 & 45.62 & 3.66 & 35.50 & 3.2 \\
\hline \multirow[t]{2}{*}{ Moderate exercise } & Garage & 24.76 & 2.81 & 29.52 & 2.13 & 30.00 & 3.45 \\
\hline & Hospital & 20.48 & 2.80 & 42.86 & 3.30 & 31.43 & 3.86 \\
\hline
\end{tabular}

